\title{
Elucidating patterns of size-dependent predation on larval yellow perch (Perca flavescens) in Lake Michigan: an experimental and modeling approach
}

\author{
Richard S. Fulford, James A. Rice, Thomas J. Miller, and Fred P. Binkowski
}

\begin{abstract}
Yellow perch (Perca flavescens) in Lake Michigan have experienced sustained recruitment failure since 1990 as a result of increased mortality during the pelagic larval phase. Increased mortality of larval yellow perch has been tied indirectly to increased alewife (Alosa pseudoharengus) predation, but effects of predation on larval survival variability must be better understood. We compared the relative importance of predation by alewife and two other fish predators to larval survival in laboratory experiments and developed an individual-based predation model (IBM) to examine patterns in size-dependent predation vulnerability. Simulations exposing larval perch to predation by all predators suggest that larval mortality resulting from alewife predation is more size-dependent than mortality resulting from the other two predators, and the range of sizes vulnerable to alewife is smaller. Alewife predation may not be an important mortality source for larval yellow perch in Lake Michigan at present because of the narrow range of vulnerable sizes and low densities of larval perch in the open lake. Predation is more likely to be important in smaller, more productive systems where other predators are abundant. Modeling results also indicate IBM analysis of date of hatch distributions of surviving larvae is a valuable tool for identifying factors most important to larval survival.
\end{abstract}

Résumé : Les perchaudes (Perca flavescens) du lac Michigan subissent un échec soutenu de leur recrutement depuis 1990 à cause d'une augmentation de la mortalité durant leur phase larvaire pélagique. La mortalité accrue des larves de perchaude a été reliée à l'augmentation de la prédation par le gaspareau (Alosa pseudoharengus), mais les effets de la prédation sur la variabilité de la survie larvaire doivent être mieux compris. Nous avons comparé l'importance relative de la prédation par le gaspareau et par deux autres poissons prédateurs sur la survie larvaire dans des expériences de laboratoire et nous avons mis au point un modèle de prédation basé sur l'individu (IBM) pour examiner les patrons de vulnérabilité à la prédation en fonction de la taille. Des simulations qui exposent des larves de perchaude à l'ensemble des prédateurs laissent croire que la mortalité larvaire due au gaspareau est plus fonction de la taille que celle due aux deux autres prédateurs et que la gamme des tailles vulnérables au gaspareau est plus étroite. La prédation par le gaspareau peut ne pas être actuellement une cause importante de mortalité chez les larves de perchaude au lac Michigan à cause de la marge réduite des tailles vulnérables et à cause des faibles densités de larves de perchaude dans les eaux du large. La prédation est vraisemblablement plus importante dans les systèmes plus petits et plus productifs où il y a abondance d'autres prédateurs. Les résultats de la modélisation montrent que l'analyse IBM de la date d'éclosion des larves survivantes est un outil précieux pour identifier les facteurs qui sont les plus importants pour la survie des larves.

[Traduit par la Rédaction]

\section{Introduction}

Annual recruitment variability in fishes is often significantly affected by survival during the larval phase. Cumulative larval mortality can be $99 \%$ or more, and relatively minor changes in this value can translate to large differences in the size of an annual cohort (Houde 1987, 1989; Sissenwine 1984). Mortality during the larval stage is particularly important for yellow perch (Perca flavescens) in Lake Mich- igan. Population levels of yellow perch in Lake Michigan have been highly variable over the last 30 years and have been in decline since 1994 (Francis et al. 1996). The present decline is widely thought to be the result of increased larval mortality (Clapp and Makauskas 2002). Increased vulnerability to size-dependent predation is one primary hypothesis for reduced survival during the larval stage.

One consequence of high larval mortality rates is that traditional approaches to analyzing patterns in survival based

Received 6 July 2004. Accepted 14 June 2005. Published on the NRC Research Press Web site at http://cjfas.nrc.ca on 24 November 2005.

$\mathrm{J} 18208$

Richard S. Fulford. ${ }^{1}$ Smithsonian Environmental Research Center, 647 Contees Wharf Road, Edgewater, MD 21037, USA.

James A. Rice. Department of Zoology, North Carolina State University, Campus Box 7617, Raleigh, NC 27695, USA.

Thomas J. Miller. Chesapeake Biological Laboratory, University of Maryland Center for Environmental Sciences, P.O. Box 38,

Solomons, MD 20688, USA.

Fred P. Binkowski. Great Lakes WATER Institute, 600 East Greenfield Avenue, Milwaukee, WI 53204, USA.

${ }^{1}$ Corresponding author (e-mail: fulfordr@si.edu). 
on the average characteristics of a cohort can be misleading because the "average" larva often does not survive (Sharp 1987). Instead, it may be more informative to ask whether the survivors of the larval phase are a random subgroup of the population or a nonrandom group that possesses some inherent advantage when compared with other members of the cohort. In cases where selective mortality occurs, an analysis of the change in key characteristics of survivors has proven valuable for detecting the causes of selective mortality in larval fishes (e.g., Crecco and Savoy 1985; Rice et al. 1987; Leggett and Deblois 1994).

Larval mortality is typically size-dependent (Miller 1988; Sogard 1997). Analysis of factors affecting size-dependent mortality in larval fishes is difficult because selective forces are hard to detect from field data (Miller 1997), and appropriate factorial experiments are often prohibitive because of time and expense. One approach that has born fruit in the past is the use of individual-based simulation models (IBM). Examination of general patterns in larval survival with IBMs has established several common threads, e.g., the intensity of size-dependent vulnerability to predation in larval fishes varies with changes in larval growth rate (Letcher et al. 1996a; Rice et al. 1993) and between predator types (Cowan et al. 1996).

In addition to growth rate variability, an often overlooked and potentially important source of size variability for a larval cohort is variation in individual date of hatch (DOH). Date of hatch often varies by days or weeks, resulting in size differences among larvae because of differences in the amount of time they have had to grow. In fact, timing of hatch may be as important, or more important, than growth rate in the development of size variability within an annual larval cohort. Variation in the timing and intensity of sizeselective predation is likely to affect the relationship between larval survival and DOH. Predator density can vary significantly over the larval period, resulting in differences in predation vulnerability over time for individual larvae because of changes in encounter rate with particular predator species (Brandt et al. 1987). It is important to understand how all aspects of size variability contribute to size-dependent predation vulnerability, and comparisons of all potential contributing factors in a modeling framework will be more informative regarding the importance of particular factors than is possible from field data alone.

We conducted a series of laboratory experiments to quantify size-dependent vulnerability of larval yellow perch to three natural predators: alewife (Alosa pseudoharengus), white perch (Morone americana), and adult yellow perch. Alewife are the most commonly cited predator of larval fishes in Lake Michigan (Crowder 1980; Shroyer and McComish 2000). White perch and adult yellow perch, while not present in the pelagic zone of Lake Michigan, would come into contact with larval perch in smaller lakes and have been observed to consume larval yellow perch if given the opportunity (Fulford 2003). We also examined how these relationships are affected by larval condition, larval density, and the presence of alternative prey. We used these data to build a predator-prey IBM that takes into account variability in both growth rate and $\mathrm{DOH}$, as well as differences in size dependence of predation among predator types. We used this IBM to examine changes in the $\mathrm{DOH}$ distribution of survivors resulting from two typical patterns of size-dependent mortality: changes in mortality resulting from changes in larval growth rate and from changes in the timing and intensity of size-selective predation. Changes in the timing and intensity of predation are hypothesized to increase the importance of $\mathrm{DOH}$ in determining the predation vulnerability of individual larvae. We ask two broad questions. Is this IBM analysis useful for interpretation of $\mathrm{DOH}$ distributions of larval yellow perch survivors? Does predation limit survival of larval yellow perch in Lake Michigan.

\section{Methods}

Larval yellow perch used in all of the experiments were hatched in the laboratory from egg skeins stripped and fertilized in the field during May from 1999 to 2001. These skeins were collected from ripe females captured in gill nets during the peak of spawning for yellow perch in Lake Michigan waters near Milwaukee, Wisconsin. Each female produces one skein per year. Up to 10 skeins were collected each season over a 1- to 2-day period, and these were individually fertilized in the field with the milt from 3 to 6 males. Fertilized skeins were returned to the Great Lakes WATER Institute Aquaculture Lab and placed on plastic platforms in a $2.4 \mathrm{~m}$ diameter tank with minimal flow and ambient temperature conditions $\left(10-11^{\circ} \mathrm{C}\right)$.

Beginning two days after egg fertilization, temperature was raised $1{ }^{\circ} \mathrm{C}$ every other day until hatching was observed. This procedure decreases development time and increases hatching success in the laboratory (Fred Binkowski, unpublished data). Hatching began within 10-14 days, and larvae were maintained in the same tank at $15{ }^{\circ} \mathrm{C}$ under flowthrough conditions for the duration of the experimental season. Larvae were fed a staged diet over the experimental period beginning with small cultured zooplankton and followed by Artemia nauplii, ground-up beef liver, and finally a commercial pellet feed. A staged feeding protocol has been shown to maximize growth and survival for yellow perch larvae in the lab (Fred Binkowski, unpublished data).

Predators used in these experiments were adult alewife, adult white perch, and adult yellow perch. In the fall of the year preceding the experiments, juvenile alewives were captured with beach seines in water less than $1.5 \mathrm{~m}$ deep from various sites near Milwaukee, Wisconsin, and were maintained in the laboratory until the following spring. Adult white perch were captured with gillnets in Green Bay, Wisconsin, in the late fall and were maintained in the laboratory until the following spring. Yellow perch were available in the laboratory from previous years' spawning activities (described above). All predators were maintained at $15{ }^{\circ} \mathrm{C}$ in flow-through systems and were fed a maintenance ration of commercial, pelleted food until the beginning of the experimental season.

\section{Probability of capture}

This experiment was conducted in June-July 1999 and June-July 2001. In 1999, an experimental system was set up consisting of eight $145 \mathrm{~L}$ rectangular tanks, each with a glass observation panel on one side. The tanks were isolated visually by surrounding them with a black plastic curtain. Each tank was covered with an opaque plastic lid fitted with 
a polyvinyl chloride (PVC) tube extending from above the tank through the cover into the tank interior. This tube was used to introduce fish larvae without disturbing the predators in the tank.

At the beginning of the acclimation period, each tank received five predators of a single species. White perch (150$193 \mathrm{~mm}$ total length, TL) were placed in four tanks and adult yellow perch (144-157 mm TL) were placed in the other four; tanks were randomly assigned to species. Total length of each individual predator was measured to the nearest $1 \mathrm{~mm}$ before introduction. These predators were allowed to acclimate to the tank for 7 days before the beginning of a trial. Trial tanks were maintained at a temperature of $17{ }^{\circ} \mathrm{C}$ and a mean flow of $3.5 \mathrm{~L} \cdot \mathrm{min}^{-1}$. The acclimation period included the introduction of yellow perch larvae as a food source to re-acclimate the predators to live food. During the acclimation period, the fish were not disturbed unless a predator died and had to be removed. Predator mortality typically occurred only in the first 1-2 days after transfer. All feeding was conducted via the feeding tube, and all feeding was halted $24 \mathrm{~h}$ before the beginning of an experimental trial.

At the beginning of an experimental trial, 25-50 yellow perch larvae were introduced into an individual test tank. From the moment of introduction, an observer watched all activity in the tank through a small observation hole cut into the black plastic screen. A second participant stood behind the tank to introduce larvae through the PVC tube, keep time, and record all observations. The observer would pick a single predator in the tank and verbally identify successful and unsuccessful strikes for $30 \mathrm{~s}$; these strikes would be recorded by the second participant. At the end of $30 \mathrm{~s}$, the observer would arbitrarily choose another predator and repeat the process. This single-predator observation method was used to minimize overestimation of capture success resulting from observer bias. Each trial lasted 30 min: an additional 25-50 larvae were introduced through the tube if larvae in the tank were more than $75 \%$ depleted prior to the 30 -min mark. If less than 10 strikes were observed in any 30-min trial, then that trial was not used for analysis. This procedure was then repeated in sequence for the remaining seven experimental tanks. Trials were conducted with larval yellow perch prey at 7 days posthatch (dph) (TL mean \pm standard deviation (SD), $7.5 \pm 0.43 \mathrm{~mm}), 15 \mathrm{dph}(9.2 \pm 0.82 \mathrm{~mm}), 30$ $\mathrm{dph}(12.8 \pm 1.29 \mathrm{~mm})$, and $45 \mathrm{dph}(23.0 \pm 1.78 \mathrm{~mm})$.

During pretrial observations in 1999, we established that alewife would not acclimate to the rectangular tanks and begin feeding within a reasonable time. For this reason, alewife trials were conducted in $2.4 \mathrm{~m}$ diameter round tanks. We also noted that normal feeding activity was observed more often if alewife were kept in larger groups, so alewife trials were conducted with groups of 50-100 alewives per tank (113-180 mm TL), rather than five as with white perch and yellow perch. Alewife trials were conducted June-July 2001 in a manner similar to that described for other predator species, with the exception that a larger number of yellow perch larvae was introduced into each tank to maintain a comparable larval density between trials.

On all trial days, a random sample of 25 larvae was removed from the main population and euthanized with tricaine methanesulfonate (MS-222). Total length was measured for each larva with an ocular micrometer to the nearest $0.1 \mathrm{~mm}$. Mean TL from these larvae was used as the larval length for each trial tank on that day. Data from this experiment were predator capture success, defined as the number of successful strikes divided by total strikes, for each tank.

We used these data to test for a significant relationship between capture success and predator-prey size ratio. We also wished to establish whether this relationship differed among predator species. The predator-prey size ratio was selected as a measure of relative size in this study because it had been used previously to describe a general relationship between relative size and probability of capture for larval prey (Miller 1988), which was used in this study as a candidate function for the model. Two model functions were tested for best fit with a least squared deviation method and compared with a coefficient of multiple determination adapted to account for differences in the number of parameters in a particular model function $\left(R_{\mathrm{a}}^{2}\right.$; Neter et al. 1990). The parameter-weighted $R_{\mathrm{a}}^{2}$ is comparable to the Akaike's Information Criterion (AIC) parameter for comparing nonnested models but allows for a clearer interpretation of absolute model fit than is possible with AIC. The first model function was a logistic regression, which has two parameters and is a generally accepted approach for analysis of binary-type data such as capture success (Pampel 2000). The second model function was an inverse negative exponential model that has three parameters and has been used to describe a general relationship between predator-prey relative size and capture efficiency for larval prey (Miller 1988). The logistic model was fit to the data with the logistic procedure in SAS (2002). The Miller model was fit to the data in the NLIN procedure with the Marquardt method of nonlinear estimation (SAS 2002). For both analyses, data were weighted by the number of strikes observed in each replicate. Both models were fit to data for all predators combined and also for each predator species separately. We chose the best model fit for the data based on which modeling approach (logistic vs. Miller and all data vs. predator-specific) resulted in the highest $R_{\mathrm{a}}^{2}$ values. For the predator-specific models, we also examined differences in the size-vulnerability relationship among predators based on changes in the model parameter estimates among predators.

\section{Condition-dependent selection}

Twelve $589 \mathrm{~L}$ round experimental tanks were set up in two sets of six and were visually isolated behind a black plastic curtain. At the beginning of the acclimation period, 10 yellow perch (144-157 mm TL) were placed in each of the six tanks in the first set and 20 alewives $(110-180 \mathrm{~mm}$ TL) were placed in each of the six tanks in the second set. The TL of each predator was measured to the nearest $1 \mathrm{~mm}$ before this introduction. Predators were then allowed to acclimate to the trial tanks for 7 days. This acclimation period included the introduction of yellow perch larvae as a food source to re-acclimate the predators to live food. Predators were otherwise not disturbed except to remove any dead fish. All feeding ceased $24 \mathrm{~h}$ before the experimental period.

On the same day that predators were moved into the trial tanks, 500 yellow perch larvae were removed from the main population and split between two $47 \mathrm{~L}$ aquaria. Temperature in the aquaria was maintained at $17{ }^{\circ} \mathrm{C}$ with a flow of 
$0.3 \mathrm{~L} \cdot \mathrm{min}^{-1}$. These larvae were fed a ration similar to that of the main population and were allowed to acclimate for 2 days; they were then starved for the remaining 5 days prior to trials. A 5-day starvation period caused a significant decline in larval nutritional condition without $100 \%$ mortality (Heyer 2000). On several occasions during the starvation period, cannibalism by larger larvae on their smaller conspecifics was observed. To maintain a representative starved group, all cannibals were excluded from the trials.

During this 5-day starvation period, otoliths of the starved larvae were marked with alizarin complexone (Letcher et al. $1996 b)$. To minimize larval mortality resulting from excessive handling or an interruption of flow in the aquarium, the alizarin was introduced to each aquarium at $25 \mathrm{mg} \cdot \mathrm{L}^{-1}$ and flow was adjusted so that the alizarin was slowly diluted out of the system over $12 \mathrm{~h}$. In preliminary trials, this protocol resulted in a reliable mark being placed on otoliths that could be used for identification (R.S. Fulford, unpublished data).

On each trial day, a random sample of 25 starved, alizarinmarked larvae (hereafter "starved larvae") were combined in a glass beaker with a random sample of 25 larvae from the main population that had been fed normally during the acclimation period. A trial was started by introducing this mixed group of larvae into one of the 12 experimental tanks selected at random. The predators in this tank were then allowed to feed for $30 \mathrm{~min}$ to $1 \mathrm{~h}$. The length of each trial was adjusted to insure a minimal amount of feeding activity but to stop the trial before excessive feeding masked the selective signature (i.e., predators may "select" a larval type first but then continue eating, thereby eliminating evidence of selection). The target was a maximum of $50 \%$ consumption per trial. Trials were limited to $1 \mathrm{~h}$ or less based on data suggesting larval yellow perch become hard to identify in predator guts after 1.5-2 h (Fulford 2003). All trials were observed to make these adjustments.

At the end of the feeding period, the predators were immediately removed from the tank and euthanized with MS-222. They were then placed on ice and their guts were removed and preserved in $95 \%$ ethanol for analysis. This procedure was repeated for each trial tank in random order. On each trial day, 25 larvae from both the main population and from the starved subgroup were euthanized in MS-222 and their total length was measured to the nearest $0.1 \mathrm{~mm}$ with an ocular micrometer. These data were used to calculate mean and standard deviation of larval size for each trial tank on that day. Experimental trials were conducted for larvae at $15,30,45$, and $60 \mathrm{dph}$.

In the lab, all larvae were removed from the guts, and both sagittal otoliths were removed from all ingested larvae. These otoliths were observed immediately for an alizarin mark, which is clearly visible on freshly removed otoliths. The numbers of larvae with marked and unmarked otoliths consumed in each trial tank were analyzed for differences in percent occurrence of starved larvae in the guts with a Chi square analysis (Neter et al. 1990).

\section{Alternative prey}

Twelve $589 \mathrm{~L}$ round tanks were used in all trials involving alewife as a predator (hereafter "alewife tanks"), and twelve
$147 \mathrm{~L}$ rectangular tanks were used in all trials involving yellow perch as a predator (hereafter "perch tanks"). The use of different tanks was a compromise based on available space and previous observations regarding tank type and predator acclimation success. Both tank sets were visually isolated behind black plastic curtains.

Twenty alewife (110-180 mm TL) or eight adult yellow perch (144-157 mm TL) were placed in each tank within the respective sets and were maintained at $17-18{ }^{\circ} \mathrm{C}$ with constant flow throughout the acclimation and experimental period. Flow in both tank types was maintained to allow for four complete exchanges of water per day. During the 7-day acclimation period, predators were not disturbed except to remove any dead fish. They were fed yellow perch larvae twice per day during the acclimation period to recondition them to a live food source. All feeding stopped $24 \mathrm{~h}$ before the beginning of experimental trials. Tanks within each species block were randomly assigned to one of six possible treatments (zooplankton present or absent $\times$ larval density $0.02,0.09$, or $\left.0.16 \mathrm{mg} \cdot \mathrm{L}^{-1}\right)$.

Zooplankton used as alternative prey were collected once per week in Lake Nagawicka (surface area $3.7 \mathrm{~km}^{2}$, mean depth $11 \mathrm{~m}$ ), an inland lake located about 30 miles west of Lake Michigan near Milwaukee, Wisconsin. Zooplankton were collected by towing a $0.5 \mathrm{~m}$ diameter, $64 \mu \mathrm{m}$ mesh plankton net $1 \mathrm{~m}$ below the surface for $10 \mathrm{~min}$ at a site in the middle of the lake (site depth $30 \mathrm{~m}$ ). Zooplankton was maintained in the laboratory with mild aeration until needed for experiments. Zooplankton represents the major component of the pelagic prey field and, as such, is the only significant alternative prey item to larval yellow perch in the pelagic zone of Lake Michigan, including other larval fishes (Fulford 2003).

Collected zooplankton was filtered at $300 \mu \mathrm{m}$ to remove small zooplankton from the assemblage before its use as alternative prey. Before the beginning of experimental trials, a mass-density relationship was established for the filtered zooplankton to ease the process of standardizing zooplankton density between trials. This mass-density relationship was established by weighing out standard aliquots of zooplankton on a $64 \mu \mathrm{m}$ filter and then counting the zooplankton in each aliquot under a dissecting microscope. Zooplankton density was set at 100 organisms $\cdot \mathrm{L}^{-1}$ for all trials in the experiment. The mass-density relationship was calculated three times during the experimental period to adjust for any changes in zooplankton species composition.

Trials were initiated by introducing prey into the tank according to treatment. For tanks receiving only larvae, the required number of larvae was poured into a length of PVC pipe plugged with a rubber stopper mounted on a plastic rod. The pipe was lowered slowly into the tank until the bottom reached a depth of about $20 \mathrm{~cm}$, and the larvae were introduced by forcing the stopper downward with the rod. For tanks receiving a mixture of larvae and zooplankton, a preweighed aliquot of zooplankton was added to the tube along with the larvae, and introductions to the predator tank were done in a similar fashion. Trials were conducted one tank at a time in random order. Once prey were introduced to a tank, predators were allowed to feed for a preset period (30 min for alewife and $45 \mathrm{~min}$ for adult yellow perch). At the end of the feeding period, all predators were immedi- 
ately removed from the tank and euthanized with MS-222. They were then placed on ice and their guts were removed for analysis. On each trial day, 25 larvae were removed from the main population, euthanized in MS-222, and measured to the nearest $0.1 \mathrm{~mm}$ TL with an ocular micrometer. These length data were used to calculate mean and standard deviation for larval size on that trial day. Trials were conducted for larvae at $15 \mathrm{dph}$ (mean $\mathrm{TL} \pm \mathrm{SD}=7.45 \pm 63 \mathrm{~mm}$ ), $30 \mathrm{dph}(9.7 \pm 1.1 \mathrm{~mm})$, and $45 \mathrm{dph}(16.4 \pm 2.3 \mathrm{~mm})$.

In the lab, all larvae and zooplankton were removed from predator guts and counted. Data consisted of total number of larvae and zooplankton consumed per minute in each tank divided by the number of predators in the tank. Data were analyzed for a significant difference in feeding rate on either larvae or zooplankton between treatments and larval sizes. Statistical comparisons for a difference in feeding rate on larvae between larvae-only and zooplankton-larvae mixed treatments were conducted with the Wilcoxin rank sum test. Comparisons for a difference in feeding rate on larvae and zooplankton between different larval densities were conducted with the Kruskal-Wallis test. Nonparametric tests were used because of heteroscedasticity caused by high feeding variability between individual predators and low sample sizes within treatments (Hollander and Wolfe 1999).

\section{Individual-based model}

The individual-based model was based on a general IBM describing size-selective predation on fish larvae (Letcher et al. 1996a). We adapted this model to account for multiple predators based on the approach of Cowan et al. (1996), and where appropriate, we changed their general model functions to functions specific to larval yellow perch based on our laboratory experiments and data from the literature.

This model describes daily predation vulnerability of individual yellow perch larvae as a function of the relative size of predator and prey (Fig. 1). Key parameters are expected daily encounter rate between a predator of size $l$ and the $i$ th larva $\left(E_{i, l}\right)$ and a size-based probability of attack and capture of a predator of size $l$ and species $k$ on the $i$ th larva $\left(\mathrm{p}_{k, i, l}\right)$. Expected daily encounter rate is based on equations derived by Gerristen and Strickler (1977) and adapted for a nontrivial prey size by Breck and Gitter (1983). Expected daily encounter rate (number $\cdot$ day $^{-1}$ ) is calculated in the model based on reactive distance $(\mathrm{cm})$ of both predator $\left(R_{\mathrm{p}}\right)$ and prey $\left(R_{\mathrm{L}}\right)$ and relative swimming speed $\left(\mathrm{cm} \cdot \mathrm{s}^{-1}\right)$ of both predator $(\mathrm{V})$ and prey (SS):

$$
E_{i, l}=\pi\left(R_{\mathrm{p}}+R_{\mathrm{L}}\right)^{2} \cdot \frac{\mathrm{SS}^{2}+3 \mathrm{v}^{2}}{3 \mathrm{v}} \cdot \text { Den } \cdot \text { Time }
$$

where $R_{\mathrm{p}}$ is equal to $0.8 \times$ predator length (Cowan et al. 1996 ), and $R_{\mathrm{L}}$ is equal to $2 \times$ larval length $\cdot \pi^{-2}$ (Bailey and Batty 1983). Larval swimming speed was calculated as a function of larval size based on laboratory observations of larval yellow perch (Houde 1969). Encounter rate is nearly constant with respect to the swimming speed of larval prey because predator swimming speed is so much higher over the range of relative sizes in the model. For eq. 1, predator density (Den) is equal to $10^{-9}$, where the denominator is the modeled water volume $(\mathrm{mL})$. Because Den equals the density of a single predator in the modeled volume of water,
Fig. 1. Flow chart summarizing the predator-prey individualbased model used for the numerical experiments.

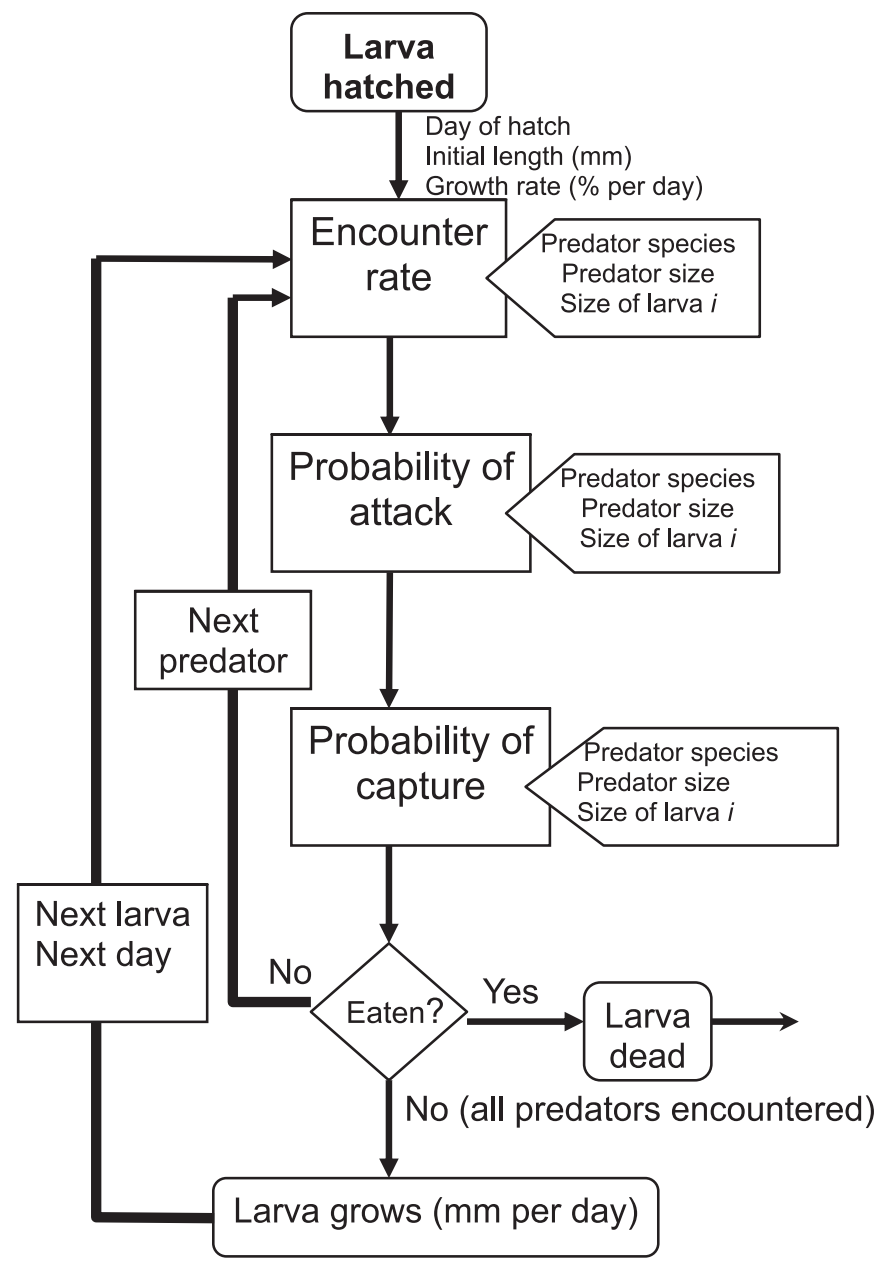

eq. 1 results in the daily encounter rate between an individual predator (randomly assigned species and length on each model day) and the $i$ th larva (Cowan et al. 1996).

Modeled water volume was based on dividing the 10000 larvae used in the model by mean larval density (number. $\mathrm{mL}^{-1}$ ) from field data for southern Lake Michigan and Green Bay $\left(1 \times 10^{-5} \cdot \mathrm{mL}^{-1}\right)$. We arbitrarily chose to use an initial larval population size of 10000 because this number was high enough to allow sufficient survivors for analysis without resulting in excessive model run time. Actual number of predators in the modeled volume was based on density data from midwater trawls and hydroacoustic analyses at several sites around Lake Michigan (30-60 fish·1000 m $\mathrm{m}^{-3}$; Fabrizio et al. 1997) and adjusted within their range in our model to achieve survival from $1 \%$ to $2 \%$ over the 45 -day model period. Equation 1 was calculated separately for each predator on a given model day.

Encounter rate was converted to expected encounters per day by multiplying by total daily feeding time (Time, $42300 \mathrm{~s}$ ). This value is based on predation occurring only during the 12-h daylight period. This is based on the observation that yellow perch larvae are only active (i.e., vulnerable to predation) during the day and represents a simplification for modeling. Actual predator activity is often 
condensed into shorter periods (e.g., dawn and dusk); however, for a comparison of vulnerability with size, this is a reasonable simplification (Cowan et al. 1996; Letcher et al. $1996 b$ ). Realized daily encounter rate between the $i$ th larva and a predator of size $l\left(\mathrm{ER}_{i, l}\right)$ is drawn randomly in the model from a Poisson distribution with $E_{i, l}$ as the rate parameter. Encounter rate did not change among predator species.

The daily probability of attack and capture $\left(p_{k, i, l}\right)$ for a predator of species $k$ and length $l$ in the model was a function of predator-prey size ratio defined empirically based on our laboratory results:

$$
p_{k, i, l}=\mathrm{CS}_{k, i, l} \cdot a_{k, i, l}
$$

where $\mathrm{CS}_{k, i, l}$ is the capture success given an attack on the $i$ th larva by a predator of species $k$ and length $l$, and $a_{k, i, l}$ is the relative attack rate on the $i$ th larva by a predator of species $k$ and length $l$.

We used the results from the capture success experiment in two ways. First, we used these data to build a predictive function for capture success based on the predator-prey size ratio. This predictive function was the best-fit equation resulting from the capture probability analysis mentioned previously. Second, we used results from the capture success experiments in the form of number of strikes per trial (both successful and unsuccessful) to develop a functional relationship between predator relative probability of attack $\left(a_{k, i, l}\right)$ and predator-prey size ratio. This approach rests on the assumption that the number of attacks observed in a fixed period is an index of the relative probability of attack based on relative size of predator and prey. We can only estimate relative probability of attack because our experimental results cannot account for tank size effects on encounter rates or for differences in encounter rate between our experimental system and Lake Michigan.

We tested for a significant relationship between probability of attack and predator-prey size ratio for each predator type and whether the slope of these relationships differed from zero using a simple linear regression analysis (SAS 2002). Probability of attack was set at 0.5 by Letcher et al. (1996a) for a general predator in order to achieve reasonable larval mortality rates in their model. We adapted this approach to allow the probability of attack to vary around a preselected mean value (0.5) based on the probability of attack-size ratio relationship established in our experiments. These two functions combined $\left(\mathrm{CS}_{k, i, l} \times a_{k, i, l}\right)$ allowed us to incorporate size- and predator-specific differences in both attack rate and capture success into our model.

Daily vulnerability of the $i$ th larva to a predator of species $k$ and length $l\left(V_{k, i, l}\right)$ is defined as the probability of an individual larva not escaping all its encounters with that predator, based on a binomial probability function:

$$
V_{k, i, l}=1-\left(1-p_{k, i, l}\right)^{\mathrm{ER}_{i, l}}
$$

where the number of trials is the realized daily encounter rate $\left(\mathrm{ER}_{i, l}\right)$ and the success probability is the probability of attack and capture $\left(p_{k, i, l}\right)$. Vulnerability for each larva on each day was compared with a uniform random number $(x)$ between 0 and 1 , and if $V_{k, i, l}$ was more than $x$, then the $i$ th larva was removed from the simulation.

\section{Numerical experiments}

The predator-prey IBM was used to address questions regarding the influence of differences in individual $\mathrm{DOH}$ on size-dependent predation vulnerability of larval yellow perch. All model runs lasted 45 days based on the estimated length of the pelagic larval period for yellow perch (3040 days). All numerical experiments were run with an initial cohort of 10000 larvae, which were introduced into the model gradually over the first 24 days of each model run. The number of individual larvae that entered the model each day was $b_{d} \times 10000$, where $b_{d}$ is a value between 0 and 1 taken from a $\mathrm{DOH}$ frequency distribution based on observed hatching patterns for yellow perch in Lake Michigan (Fulford 2003). Both initial size and individual growth rate were randomly assigned to each larva at the beginning of the model run based on respective normal distributions. The mean and variance of initial larval size (mean \pm SD, $5.7 \pm$ $0.13 \mathrm{~mm}$ ) were based on hatch size data collected in the laboratory (R. Fulford, unpublished data). The mean and variance for larval growth rate were manipulated as a part of the numerical experiments (see below). Therefore, size variability for larvae in the model reflected the combined effects of variation in initial size, growth rate, and timing of hatch. Each numerical experiment consisted of three replicate model runs to account for model stochasticity.

First, we investigated how DOH distributions of survivors are affected by changes in size variability within cohorts caused by interannual changes in mean growth rate. Previous research has shown that changes in mean growth rate between cohorts can result in changes in the size dependence of larval vulnerability to predation (Cowan et al. 1996; Rice et al. 1993), and we wished to investigate how these changes are reflected in the $\mathrm{DOH}$ distribution. We conducted model runs at two mean growth rates $(2 \%$ and $4 \%$ per day, SD $0.1 \%$ for both) representative of the range of mean growth rates we observed for larval yellow perch in Lake Michigan. We also conducted model runs in which larvae were exposed to mortality of a similar magnitude that was independent of larval size. These three scenarios were hypothesized to result in a range of size dependence, measured as the daily mean difference in length between survivors and nonsurvivors. We further hypothesized that these differences in the size dependence of mortality would be reflected as differences in the $\mathrm{DOH}$ distribution pattern of survivors. Output for the growth rate variability experiment was cohort survival, daily mean length of survivors and nonsurvivors, and DOH distribution of survivors. Simulations were conducted for each predator type (alewife, white perch, and adult yellow perch) to assess predator-specific differences in size selectivity. Predator density was set at 0.045 predators $\cdot \mathrm{m}^{-3}$ based on mean density data for predators in Lake Michigan (Fabrizio et al. 1997).

The second numerical experiment addressed how patterns in survival and DOH distribution of survivors were affected by a simulated predation pulse. Increased vulnerability to mortality was simulated with a five-day period of predation occurring at different times throughout the larval period (days 0-5, 6-10, 11-15, 16-20, 21-25, 26-30, 31-35, 3640, and 41-45). Predator density during the predation pulse was $0.045 \mathrm{~m}^{-3}$, and mean larval growth rate was set at $4 \%$ 
per day (SD $0.1 \%$ per day) for all simulations. Output for the timing of predation experiment was total larval survival and $\mathrm{DOH}$ distribution of survivors for each model run.

\section{Results}

\section{Probability of capture}

Capture success of individual predators feeding on larval yellow perch varied with predator-prey size ratio for all predator species tested (Fig. 2). Capture success was low for the smallest size ratios and rose monotonically with increasing size ratio. For white perch and yellow perch predators, maximum capture success was achieved around a predatorprey size ratio of 12-14 and remained high for all larger size ratios tested. Trials that involved predation by alewife at larger size ratios (i.e., smallest larvae) resulted in no attacks. As a consequence, alewife displayed an ascending pattern similar to those of the other two predators at lower size ratios but no evidence that capture probability was maximized over a wide range of size ratios, as was indicated for white perch and adult yellow perch. Capture probability also differed in variability between predator species. Maximum observed capture probability was high for all three predator species (alewife, 1.0; white perch, 1.0; yellow perch, 0.94); however, the observed values for alewife were much more variable than for the other two species.

We used these data for capture success as a function of predator-prey size ratio to develop a predictive relationship that could be used in the individual-based model. The logistic model performed better than the Miller model when both functions were fit to the data for all three predators combined, but the $R^{2}$ value for both models was generally low (Table 1). However, model fit was noticeably improved when data for each predator species were fit separately, which suggests the capture success - size relationship differs between species. Further, $R_{\mathrm{a}}^{2}$ values were higher for the speciesspecific fit of the Miller model for all three predators compared with the species-specific fit for the logistic model (Table 1). Based on a comparison of parameter estimates for the predator-specific Miller model, differences in the relationship between capture success and relative size among predators are largely due to differences between alewife and white perch, with values for all three parameters for adult yellow perch falling between those of the other two predators (Table 1; Fig. 2). Given these results, we used the predatorspecific Miller model to predict capture success as a function of predator-prey size ratio for each predator species in the model simulations.

\section{Relative probability of attack}

Predator interest measured as the number of strikes (successful and unsuccessful) observed in each 30-min trial also differed among predator species (Fig. 3). Predator interest of alewife feeding on yellow perch larvae declined significantly with increasing size ratio (strikes $=-1.2$ (size ratio) +33.2 ; $t$ test, $p<0.001)$. In contrast, white perch showed a positive linear relationship between predator interest and size ratio; however, the slope of this relationship did not differ from zero $($ strikes $=0.44($ size ratio $)+8.3 ; t$ test, $p=0.18)$. Adult yellow perch showed no detectable change in their interest
Fig. 2. Capture success measured as the number of successful captures/number of strikes for (a) alewife (Alosa pseudoharengus), (b) white perch (Morone americana), and (c) adult yellow perch (Perca flavescens) feeding on larval yellow perch. The diamonds are experimental data and the line is the best fit of the Miller model. Black triangles on the alewife chart indicate size ratios at which all trials resulted in no attacks.
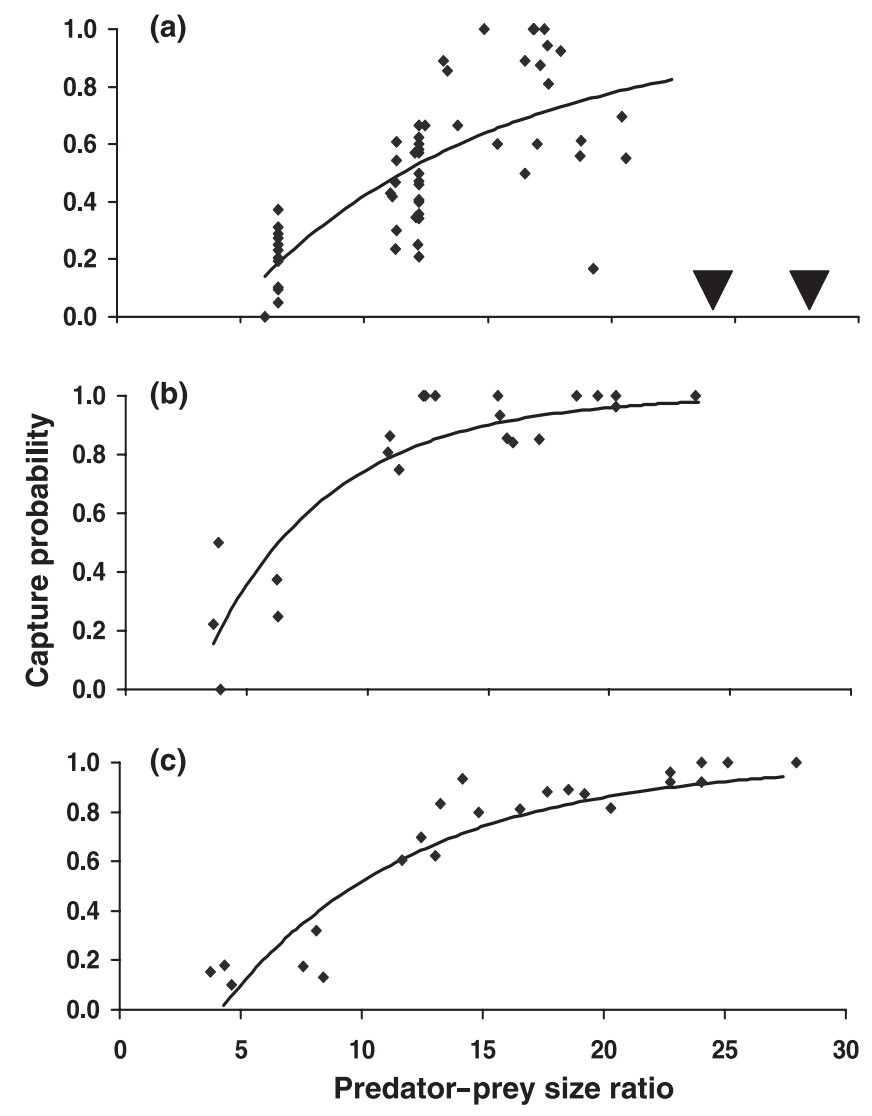

over the tested range of size ratios (strikes $=0.09($ size ratio $)+$ 19.4; $t$ test, $p=0.62$ ).

These data were used to adapt a general probability of attack parameter for predators preying on larval fishes into a size-based function that varied in shape among predator species but had the same mean value. A function describing relative probability of attack $\left(a_{k, i, l}\right)$ for the $i$ th larva by all predators encountered of species $k$ and size $l$ was constructed by assuming relative probability of attack will be zero at size ratios where no strikes were observed and maximum probability of attack would occur at size ratios where the maximum number of strikes was observed for each predator species. Finally, the overall mean value of $a_{k, i, l}$ across all predators and size ratios was set to 0.5 for all simulations. The conversion of strikes data to $a_{k, i, l}$ took the following general form:

$$
\begin{aligned}
& \text { strikes }=m(\text { size ratio })+b \\
& a_{k, i, l}=\left(1 / \max _{k}\right) \text { strikes }
\end{aligned}
$$

where strikes equals the number of strikes in 30 min predicted based on the experimental data for a predator of species $k$ and length $l$, and $\max _{k}$ is the maximum number of 


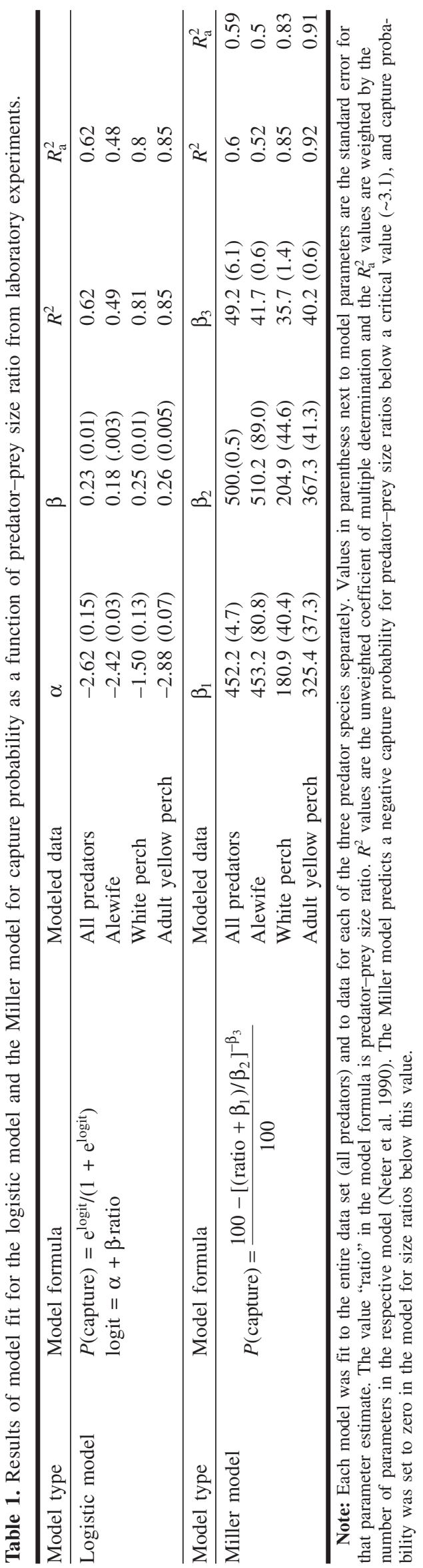

Fig. 3. Predator feeding interest defined as the total number of strikes made in $30 \mathrm{~min}$ as a function of predator-prey size ratio (ratio) by ( $a$ ) alewife (Alosa pseudoharengus), $(b)$ white perch (Morone americana), and (c) adult yellow perch (Perca flavescens) feeding on larval yellow perch. The diamonds are experimental data and the line is a best-fit linear function. The best-fit linear function, standard error for the slope $\left(\mathrm{SE}_{\text {slope }}\right)$ and intercept $\left(\mathrm{SE}_{\text {int }}\right)$, and $R^{2}$ are given for significant trends.
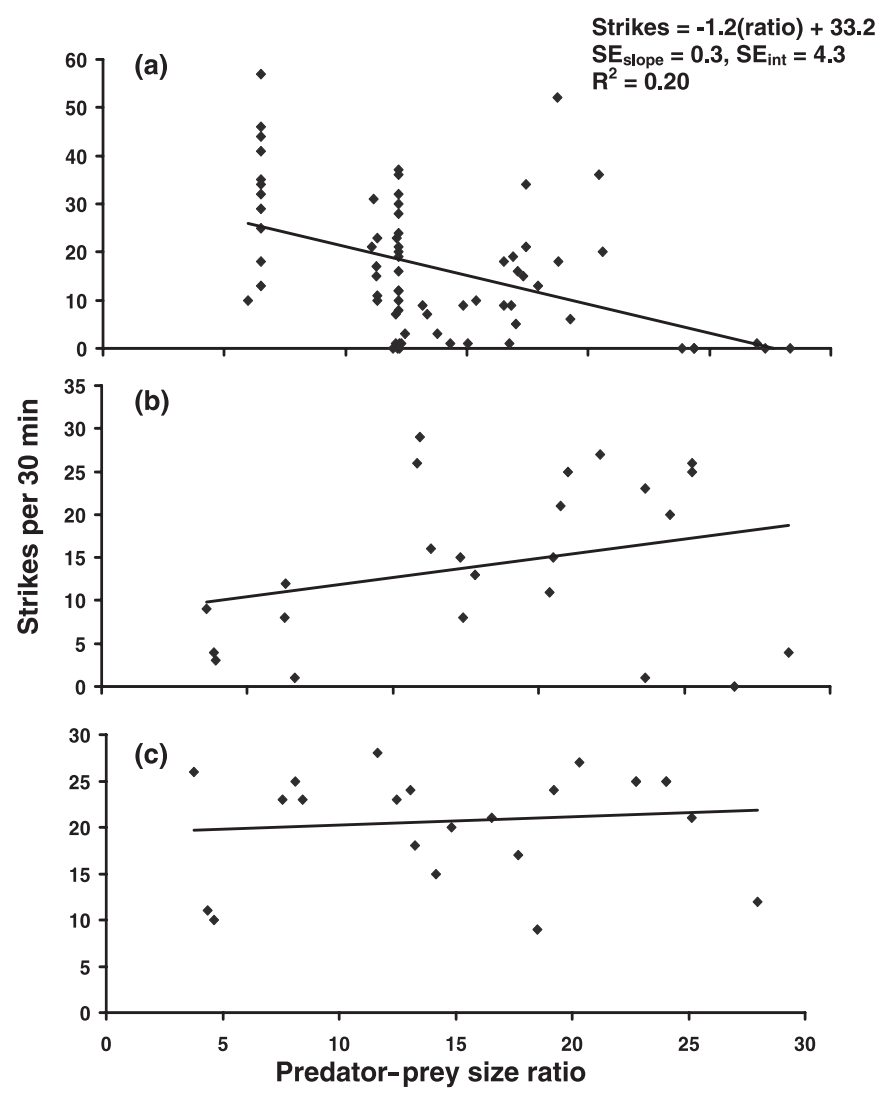

strikes predicted for a predator of species $k$. This relationship is based on the assumption that under constant conditions changes in predator interest with predator-prey size ratio reflect changes in relative probability of attack as a function of relative size. Only the strikes per trial - size ratio function for alewife displayed a slope significantly different from zero, so alewife relative probability of attack changed with size in the model. Relative probability of attack for white perch and adult yellow perch was set to 0.5 .

\section{Condition-dependent selection}

Mean length of larvae did not differ between the starved and fed treatment groups ( $t$ tests, $p<0.02$ all dates; Table 2). Across all trials used for analysis, predators consumed an average of $37 \%(10 \%-60 \%)$ of larvae in an individual trial. In most cases, both alewife and adult yellow perch showed no significant selection for or against starved larvae (Fig. 4). The only exception was that alewives captured starved larvae more often than unstarved larvae at $30 \mathrm{dph}$ when predatorprey size ratios were between 11 and 14, which is near the optimal size ratio for attack and capture for alewives $\left(\chi^{2}=\right.$ $5.89,1 \mathrm{df}, p<0.03)$. We did not detect significant conditiondependent selection by alewives at any other size ratio. Yel- 
Table 2. Summary data for mean total length $(\mathrm{mm})$ of larvae used in the conditiondependent selection experiment.

\begin{tabular}{llccc}
\hline & \multicolumn{4}{l}{ Mean total length (range) } \\
\cline { 3 - 5 } $\begin{array}{l}\text { Larval age, days } \\
\text { after hatch }\end{array}$ & $n$ & Fed larvae & Starved larvae & $p$ value \\
\hline 15 & 25 & $8.7(8.0-10.1)$ & $8.6(7.9-10.0)$ & 0.52 \\
30 & 25 & $12.7(11.4-14.4)$ & $12.2(11.4-13.1)$ & 0.23 \\
45 & 25 & $20.2(14.1-24.4)$ & $20.1(14.6-24.1)$ & 0.95 \\
60 & 25 & $36.6(27-46)$ & $33.4(26-41)$ & 0.21 \\
\hline
\end{tabular}

Note: Data are presented separately for the starved and fed treatment groups and $p$ values are given for a $t$-test testing for differences in mean length between treatment groups.

Fig. 4. Probability ( \pm 1 standard error) that a larva captured by either alewife (Alosa pseudoharengus; solid bars) or adult yellow perch (Perca flavescens; open bars) in mixed-condition prey experiments was starved. Trials were conducted at 15, 30, 45, and 60 days after hatch. Mean total length of larvae in each age treatment is given in parentheses. The reference line at 0.5 indicates random selection; however, statistical results reported are based on a chi-square analysis.

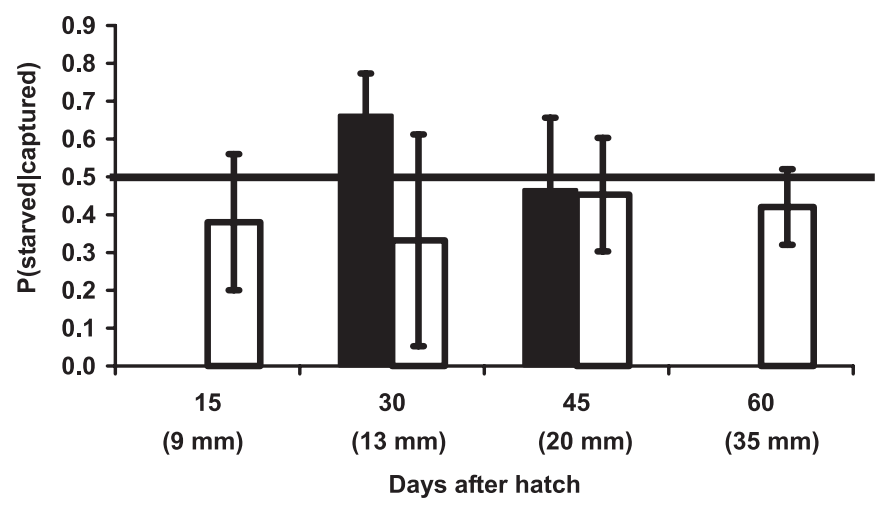

low perch displayed no significant condition-dependent selection at any size ratio tested $\left(\chi^{2}<3.4\right.$ all sizes, $1 \mathrm{df}, p>$ $0.05)$.

\section{Alternative prey selection}

Both alewife and adult yellow perch fed during this experiment on both larval yellow perch and zooplankton. Zooplankton used as alternative prey consisted of more than $70 \%$ copepods with the remainder a mix of large and small cladocerans. Alewives fed consistently on zooplankton, but feeding rate showed no trend with larval biomass (KruskalWallis $H=0.52, p>0.3)$. Feeding rate for adult yellow perch on zooplankton was low, occurring in only two out of 18 trials, with no trends evident in these data as a function of larval biomass.

Feeding rates (larvae per minute) as a function of size ratio for both predators were consistent with results from the capture success experiments. We observed maximum feeding rate in this experiment at about the same size ratio at which we would predict maximum probability of attack and capture based on the results of the capture success experiment (Fig. 5). A positive functional response was observed for alewife feeding on larval yellow perch (Fig. 6); however, this result was not statistically significant (Kruskal-Wallis $H=0.92, p>0.2)$. The presence or absence of alternative
Fig. 5. Probability of attack and capture estimated from capture success experiments (line) and feeding rates measured in the alternative prey trials (bars; \pm 1 standard error) for $(a)$ alewife (Alosa pseudoharengus) or (b) adult yellow perch (Perca flavescens) feeding on larval yellow perch. Feeding rates are the combined mean of zooplankton-present and zooplankton-absent trials conducted at each predator-prey size ratio.

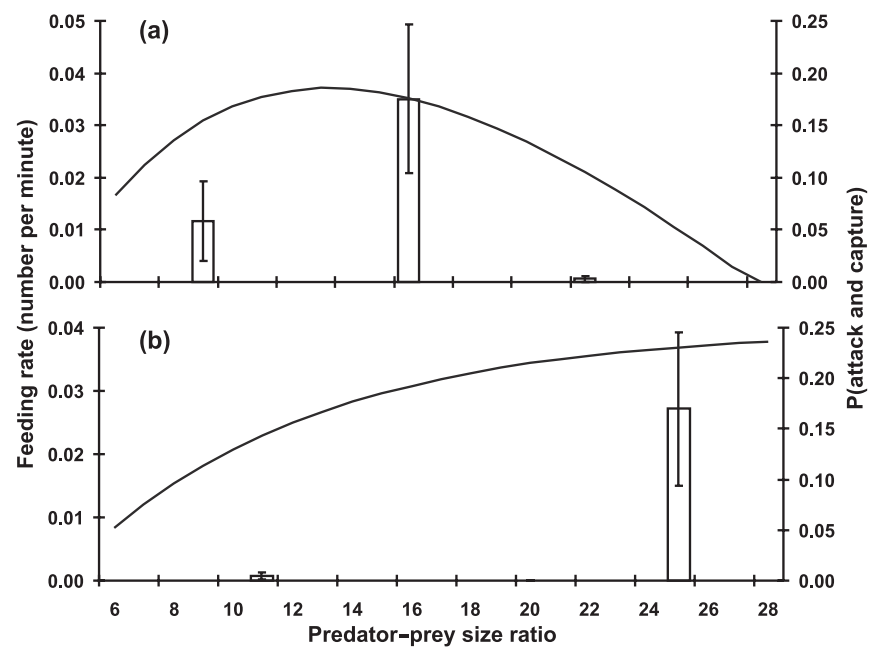

prey did not significantly affect alewife feeding rates on larvae (Wilcoxin statistic $0.63, p>0.05$ ). We did not observe any trend in functional response for adult yellow perch feeding on larvae (Fig. 6; Kruskal-Wallis $H=0.52, p>0.3$ ). However, the feeding rate of adult yellow perch on larvae was 2-3 times higher in the presence of alternative prey than without alternate prey (Fig. 6; Wilcoxon statistic 1.8, $p<$ $0.05)$.

\section{Numerical experiments}

\section{Growth rate variability and predator species comparison}

Vulnerability of larval yellow perch to predation generally increased with predator size and decreased with increasing larval size. The shape of these relationships shifted among predator species in accordance with predator-specific differences observed in the capture probability experiments. Vulnerability of larval yellow perch to both white perch and adult yellow perch rose monotonically as a function of predator size and was near the maximum vulnerability at a predator size of $160 \mathrm{~mm}$ TL for all larval sizes tested (Fig. 7). However, at predator sizes below $160 \mathrm{~mm}$ TL, larval vulner- 
Fig. 6. Feeding rate for (a) alewife (Alosa pseudoharengus) and (b) adult yellow perch (Perca flavescens) on larval yellow perch at three larval densities $\left(0.02,0.09\right.$, and $\left.0.16 \mathrm{mg} \cdot \mathrm{L}^{-1}\right)$ : solid bars, zooplankton-absent treatments; open bars, zooplankton-present treatments. Zeros on graph indicate treatments where no predator feeding occurred.

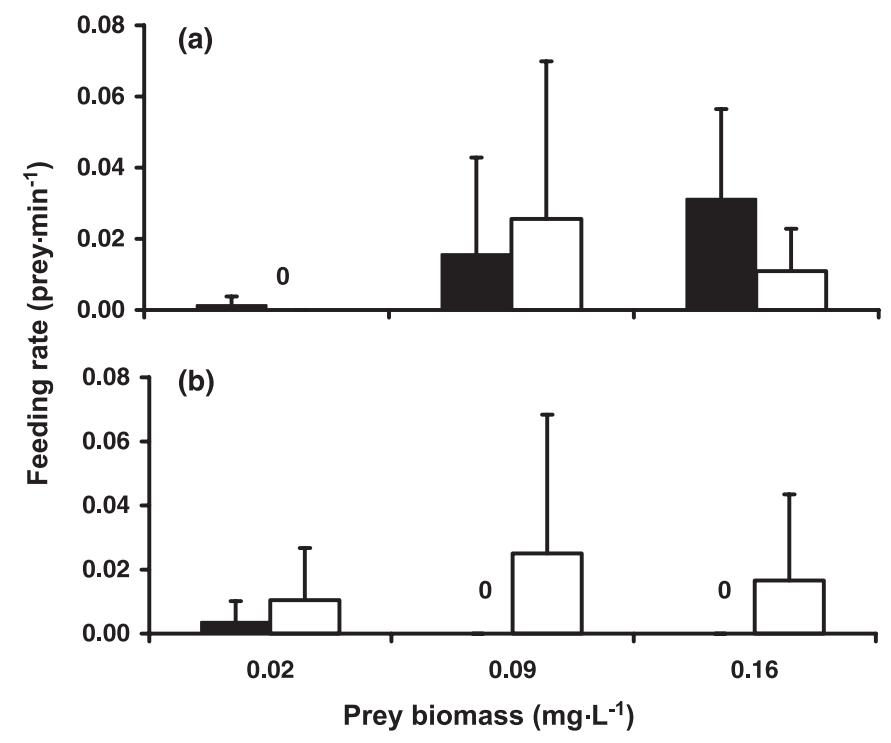

ability to predation dropped rapidly with increasing larval size when the predator was either alewife or adult yellow perch. In contrast, the slope of the relationship between vulnerability and larval size when the predator was white perch was much shallower, suggesting that larval yellow perch grow out of the vulnerability window to predation by white perch more slowly and larvae are likely to remain vulnerable to white perch for more of the larval period.

Larval vulnerability to alewife predation was more parabolic in nature than vulnerability to white perch or adult yellow perch with a size refuge evident for both the smallest and the largest larvae (Fig. 7). Larval vulnerability to predation by alewife was maximized for the smallest range of predator and larval sizes, and larval vulnerability to alewife dropped much more rapidly as larvae grew than did vulnerability to white perch or adult yellow perch. Of the three predators, vulnerability to predation by alewife appears the most strongly dependent on larval size.

At comparable predator densities, larval yellow perch survival over 45 days was lowest with white perch as predators (mean survival $(S)=0.007$ ) and highest with alewife as predators $(S=0.02)$ across both growth rates tested. However, these differences in survival among predators did not translate into measurable differences in the size or DOH distributions of larval survivors (Kolmogorov-Smirnov test, $p>$ 0.1 for size and DOH). Survival rate also changed as a function of larval growth rate. Mean survival over 45 days was lower at the low growth rate $(2 \%$ per day; $S=0.008)$ than at the high growth rate ( $4 \%$ per day; $S=0.018$ ) across all predator types.

The outcome of size-dependent predation, measured as the maximum difference in mean length between larval survivors and nonsurvivors, did not differ noticeably among predators but increased in response to increases in mean
Fig. 7. Larval yellow perch (Perca flavescens) vulnerability to predation as a function of both predator total length (Pred TL, mm) and larval total length (Larval TL, mm) for (a) alewife (Alosa pseudoharengus), (b) white perch (Morone americana), and (c) adult yellow perch as predators. Surface plots are based on a deterministic calculation of model functions.
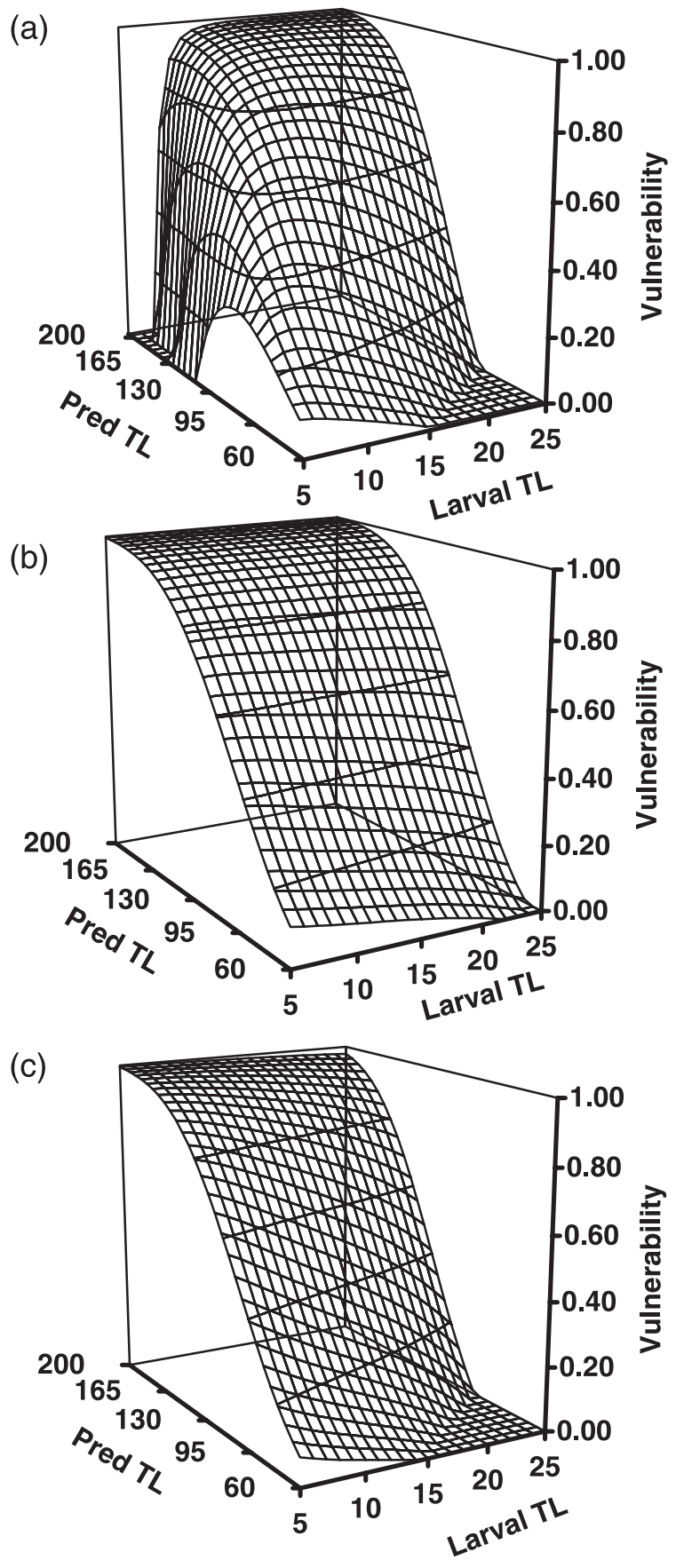

growth rate (Fig. 8). As expected, nonselective model runs showed no size difference between survivors and nonsurvivors. Maximum size difference (mean across all predators) increased to $1.3 \mathrm{~mm}$ at a mean growth rate of $2 \%$ per day and $6.5 \mathrm{~mm}$ at $4 \%$ per day. Length differences between survivors and nonsurvivors became positive around day 25 independent of changes in mean growth rate. These results are consistent 
Fig. 8. Daily mean difference in total length (TL) between survivors (alive TL) and nonsurvivors (dead TL) for larval yellow perch (Perca flavescens) resulting from model runs $(n=3$ per treatment) conducted with $(a)$ size-independent mortality and $(b$ and $c$ ) sizedependent mortality at a mean larval growth rate of $(b) 2 \%$ per day and $(c) 4 \%$ per day. Results are given for simulations run separately for alewife (Alosa pseudoharengus; circles), white perch (Morone americana; triangles), and adult yellow perch (squares).
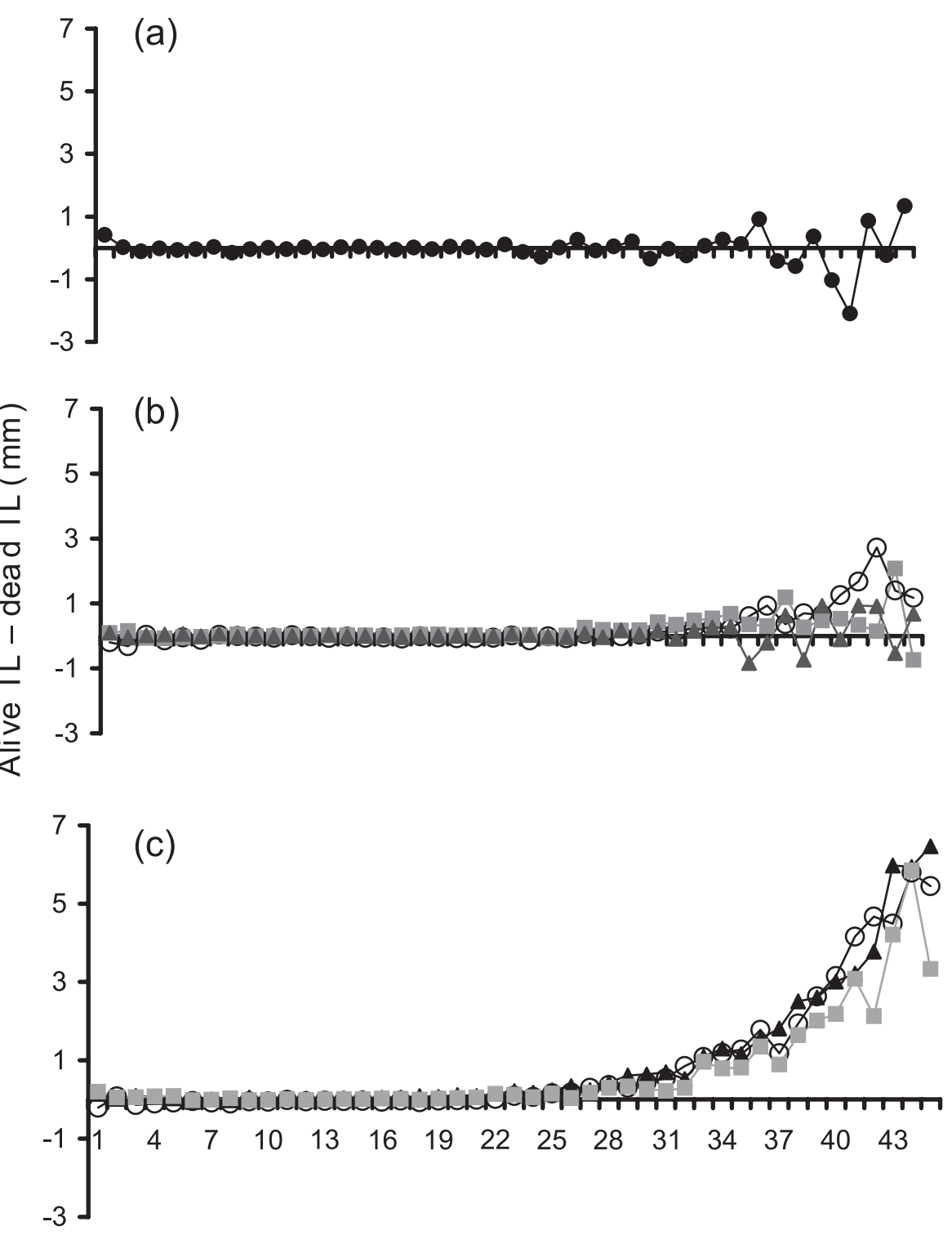

Model day

with prior IBM analyses of larval vulnerability to predation (Cowan et al. 1996; Rice et al. 1993) based on size and demonstrate that the model is appropriately describing a range of intensity for size-selective predation against which we can compare patterns in the DOH distribution of survivors.

Observed changes in the DOH distribution of larval survivors on model day 45 (i.e., end of the larval period) were associated with observed changes in size selectivity. Mortality in the model that was not size selective resulted in a hatch date distribution favoring later-hatched larvae by the end of the larval period because of their shorter duration of exposure to mortality (Fig. 9). We observed minimal difference between the DOH distribution of survivors subjected to sizedependent predation at a larval growth rate of $2 \%$ per day and the DOH distribution of survivors subjected to mortality that was not size-dependent. In contrast, when the growth rate of the larval cohort was raised to $4 \%$ per day, the $\mathrm{DOH}$ distribution of survivors more closely resembled the initial $\mathrm{DOH}$ distribution.

However, a more detailed examination of DOH distributions over the simulation period revealed a more complex pattern. On model day 25, the DOH distributions of survivors were similar among the three scenarios (non-size-selective, low growth, and high growth), shifted somewhat to a later DOH. In fact, it appears that it was only in the later larval period between day 25 and day 45 that $\mathrm{DOH}$ distributions in the high growth scenario deviated from the other two, shifting back towards earlier DOH. Day 25 is also close to the 
Fig. 9. Date of hatch frequency distribution on model days 25 (open bars) and 45 (solid bars) compared with initial hatch date distribution (line) for $(a)$ nonselective mortality simulations and ( $b$ and $c$ ) simulations of size-selective predation by alewife (Alosa pseudoharengus) with (b) low (2\% per day) and (c) high (4\% per day) mean larval growth rate.
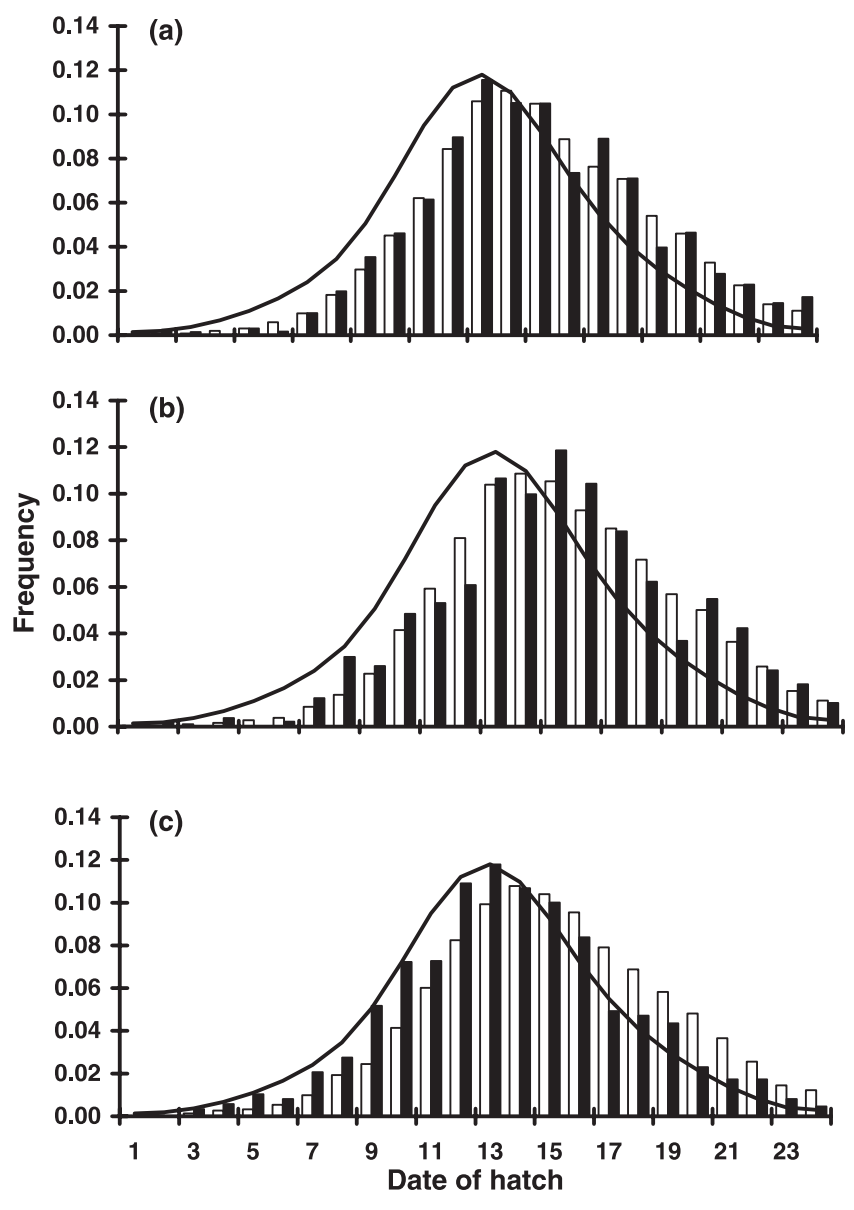

time that size dependence became detectable in individual larval survival (Fig. 8). When growth rate and DOH vary independently, non-size-selective larval mortality seems to favor later-hatched larvae as they have had less exposure to predation, and the onset of size dependence in larval mortality is correlated with a decrease in survival of late-hatched larvae because they are the smallest larvae in the system.

\section{Predation pulse experiment}

For an analysis of the effects of a predation pulse on larval survival, we chose to use only alewife as a predator in model simulations. Alewife are of particular interest as a predator of larval yellow perch in several systems, including Lake Michigan. Further, vulnerability of yellow perch larvae to alewife also appeared the most divergent from general vulnerability patterns described previously (Cowan and Houde 1992; Letcher et al. 1996a) and, as such, merits closer scrutiny.

The simulated 5-day predation window resulted in $\mathrm{DOH}$ distributions of survivors with two basic patterns, depending on how close the predation window was placed to peak hatch. Survival was high when predation was focused during the early-larval period, as most larvae had not yet hatched
Fig. 10. Forty-five day larval survival predicted in model runs simulating a 5-day period of predation occurring at different times throughout the larval period. Hatching period for larval yellow perch (Perca flavescens) in the model is indicated by the shaded bar, and peak hatch is indicated by the black arrow.

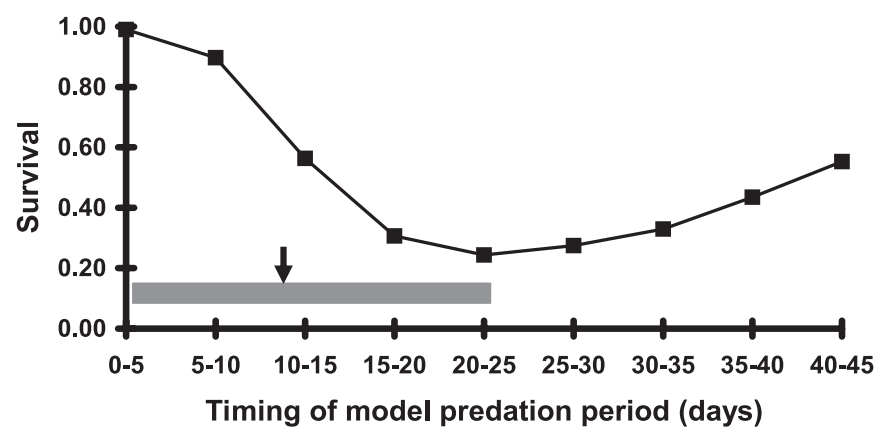

and fewer larvae were exposed to predation (Fig. 10). When the predation window occurred between day 25 and the end of the simulation, cohort survival once again increased, because as predation occurred later in the larval period, more larvae had reached a size at which size-dependent vulnerability to predation was decreasing.

Timing of predation also affected patterns within the $\mathrm{DOH}$ distribution (Fig. 11). Predation during the early hatching period generated little change in the DOH distribution, as most larvae were not available to be captured at this time. When the predation window occurred close to the timing of peak hatch (days 11-15), later-hatched larvae were overrepresented in the final DOH distribution, suggesting a survival advantage for these larvae. When the predation window occurred just after peak hatch (model days 16-20), later-hatched larvae were again overrepresented, but the survival advantage was reduced in comparison to predation around peak hatch. Finally, when the predation window occurred after day 20 in the model, the DOH distribution resembled the initial distribution with no apparent survival advantage as a function of $\mathrm{DOH}$.

\section{Discussion}

Predation vulnerability of larval yellow perch is affected by larval and predator size, as well as predator species. Capture probability increased with increasing size ratio for all three predators in laboratory experiments, but unlike that for white perch and adult yellow perch, interest in larval prey by alewife decreased and actually dropped to zero with increased predator-prey size ratio, that is, they ignored small larvae. Larval vulnerability to predation by either white perch or adult yellow perch is largely a function of larval escape capacity, but larval vulnerability to predation by alewife is a function of both larval escape capacity and the probability that alewife will attack. Therefore, vulnerability of larval perch to alewife predation as a function of size is more complex than vulnerability to other fish predators.

Our findings regarding differences in larval capture probability as a function of relative size are affected to some degree by our choice of both a relative size metric and a functional relationship between relative size and probability of larval capture. The model function used to describe the size - capture success relationship was based on a general 
Fig. 11. Initial date of hatch distribution (DOH; line) and $\mathrm{DOH}$ frequency distributions of larvae surviving to the end of the larval period (solid bars; model day 45) predicted by the model from simulating a 5-day predation window on model days $(a) 6-$ 10, (b) 11-15, (c) 16-20, and (d) 21-25. Distributions resulting from predation later in the larval period did not differ from that caused by predation during days $21-25$ and therefore are not shown.
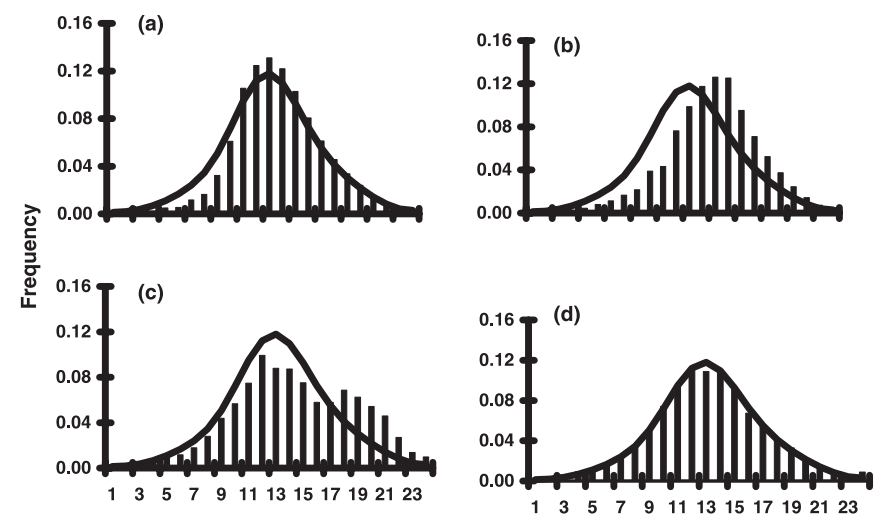

Date of hatch

function presented by Miller (1988) in their literature review of size-dependent processes to describe a relationship between predator-prey size ratio and larval capture success. No single function will completely describe all of the variability observed in our laboratory data, especially for alewife. However, our objective was to describe general patterns in larval survival between different predators and as a function of larval growth rate and DOH. The Miller model is well suited to these objectives.

Several relative size metrics have been suggested in the literature for describing size-dependent processes in fish predation, including predator-prey size ratio (Miller 1988; Letcher et al. 1996a), prey-predator size ratio (Pepin et al. 1992), and prey length - predator gape (Scharf et al. 2000). Measures of predator gape may incorporate differences among predators better than predator length, but no consensus exists on a single most useful metric of predator-prey relative size. We chose the predator-prey size ratio for this analysis because this metric incorporates commonly collected data on fish predators and is easily comparable across broader taxonomic boundaries.

The relationship between predation vulnerability and relative size has been explored previously for larval prey, and the pattern exhibited by white perch and adult yellow perch is similar to patterns described for generic fish predators (Bailey and Houde 1989; Cowan and Houde 1992). Vulnerability was high for newly hatched larvae and dropped slowly with increasing larval size until larvae reached a threshold length, at which point vulnerability dropped rapidly to zero (Cowan et al. 1996; Paradis et al. 1996). In addition, our observed threshold for the transition away from maximum vulnerability occurred at a size ratio close to 10 , which is the size ratio of maximum larval vulnerability reported by Paradis et al. (1996) based on their review of the literature.

In contrast, the pattern for alewife did not match these generic patterns for fish predators well. Alewife made no attacks on the smallest larvae. When they did attack, capture efficiency was maximized for only a narrow band of predator-prey size ratio (14-18). Further, alewife were more selective at these size ratios for larvae in poor nutritional condition. Through all of our experiments, alewife showed the highest capture efficiency for larvae when the size ratio was in this range. This is a vulnerability - relative size relationship previously ascribed to raptorial predators and suggests a more complex size-vulnerability relationship for alewife preying on larval fishes than has been observed for other planktivorous fishes (Cowan et al. 1996). Alewife capture efficiency for larval yellow perch likely differs from other planktivores because alewife exhibit behavioral plasticity in feeding behavior in response to prey type and density.

Janssen (1976) described two feeding modes for alewife: particulate feeding and filter feeding. Particulate feeding is hypothesized to be more selective as alewife are choosing prey visually and are more likely to attack larger, more active prey items based on an optimal feeding model (Crowder and Binkowski 1983). Filter feeding is largely not size selective as the alewife are simply collecting all prey in their path and prey are captured or not based largely on their inherent escape abilities. The shift between feeding modes is based on prey density, prey size, and predator size (Janssen 1976).

Similar laboratory studies of other facultative filterparticulate feeders, such as walleye pollock (Theragra chalcogramma; Ryer et al. 2002) and herring (Clupea harengus; Gibson and Ezzi 1992), demonstrate that switching from filter to particulate feeding as prey become larger and less abundant has energetic advantages as filteringefficiency drops. However, this switch also appears associated with a switch from mechanosensory to visual foraging (Ryer et al. 2002), which may provide a refuge for larger, less abundant, yet less visible prey like early-stage larval fishes.

Alewife appear to feed on larval yellow perch in a particulate mode most of the time, and the lack of interest shown by alewife for the smallest larvae in our experiments may have resulted from these larvae being visually undetectable to alewife. Alewife do feed in a particulate manner on smaller organisms such as Daphnia and mysids; however, these organisms have more pigmentation and rigid body parts that make them more easily detected. It is reasonable to assume that alewife might filter-feed on yellow perch larvae if they were present in sufficient densities, which would increase attacks on smaller larvae.

Alewife behavior also changed as larval density increased. Alewife always fed on larvae at densities above $100 \mathrm{~m}^{-3}$, but they fed intermittently, if at all, below this density. Further, feeding rate was positively associated with larval density when larvae were between 7-9 mm TL. In general, a high level of alewife predation on larval yellow perch is predicted to occur if larvae and alewife interact at or near the optimal size ratio and if larval densities are high. This conclusion is supported by observations of alewife predation on larval yellow perch in other systems. Brandt et al. (1987) documented massive predation by alewife on larval yellow perch in a small embayment adjacent to Lake Ontario. They reported that predation was highest in years when alewife interacted with larvae between 7 and $9 \mathrm{~mm}$ TL at a larval density of $79 \mathrm{~m}^{-3}$, but they observed less predation when alewife did not appear until larvae were larger. Moreover, they reported 
that incidence of yellow perch larvae in alewife stomachs declined to less than $1 \%$ at a larval density of $11 \mathrm{~m}^{-3}$, despite the larvae being an optimal size. Luecke et al. (1990) also observed that alewife show a positive functional response to larval bloater at densities exceeding $100 \mathrm{~m}^{-3}$, but feeding rate was near zero by alewife at a larval density of $50 \mathrm{~m}^{-3}$.

Larval yellow perch densities this high are rare in Lake Michigan. Larval densities in Green Bay, a shallow, productive embayment of Lake Michigan at the lake's northwest corner, have peaked at $18 \mathrm{~m}^{-3}$ in recent years (Brian Belonger, Wisconsin Department of Natural Resources, Peshtigo, Wisconsin, unpublished data), and the maximum density for larval perch from our sampling in the main body of Lake Michigan in 1998-2001 was less than $1 \mathrm{~m}^{-3}$ (Fulford 2003). These field densities support the results of our study that alewife predation is likely not a significant limiting factor for yellow perch larval survival at present.

Vulnerability of larval yellow perch to predation by both white perch and adult yellow perch remained high for a wider range of predator-prey size ratios in comparison to alewife. Moreover, larval vulnerability to these predators was not dependent on larval density. White perch and adult yellow perch should affect larval survival over a longer portion of the larval period than alewife and have a more significant effect on year-class strength when these predators are present. However, white perch are not abundant in the main body of Lake Michigan and adult yellow perch are found primarily in deeper water away from the pelagic zone, so these two predators are also not likely to have a strong influence on the survival of larval yellow perch in Lake Michigan. Overlap between larval perch and both white perch and adult yellow perch is likely to be higher in smaller, shallower systems such as Green Bay. Both predators are abundant in Green Bay and the limited depth makes spatial overlap more likely compared with a deeper, more open system like Lake Michigan. At present, predation does not appear to be a significant factor limiting larval yellow perch survival in Lake Michigan.

One interesting finding regarding larval vulnerability to predation by adult yellow perch was that feeding rate of adult yellow perch on larval yellow perch increased if alternative prey were present. Intracohort cannibalism has been reported for natural populations of European perch (Perca fluviatilis; Brabrand 1995) and for adult yellow perch feeding on young-of-the-year perch in Oneida Lake, New York (Tarby 1974), but the general importance of cannibalism to recruitment has not been well explored.

Two causes for an increase in feeding rate by adult yellow perch in the presence of alternative prey seem plausible: either adult yellow perch were simply responding to a generic increase in prey density and this was a functional response, or the foraging activity of the larval yellow perch brought on by zooplankton being present made them more vulnerable to predation. It is not possible to draw conclusions regarding the veracity of these two hypotheses from our data because we did not monitor larval activity or examine the guts of larvae to check for feeding activity. However, in all of our trial tanks, only a few adult yellow perch fed on zooplankton and they showed no evidence of a functional response. The fact that adult yellow perch did not show a functional response to an increase in the density of larvae or zooplankton suggests that selectivity for these prey is low and supports the idea that larvae are more vulnerable to cannibalism when actively feeding. Anecdotal observations of feeding behavior during our probability-of-capture experiments indicated that adult yellow perch remain near the bottom of the tank, while larvae occupied the upper third of the tank. This behavioral separation likely contributed to the lack of an observed functional response, as adult yellow perch are preying principally on larvae that "stray" closer to the bottom and the frequency of straying may not change with larval density. As a result, adult yellow perch did not appear to actively search for prey near the surface, and observed attacks were initiated in response to some visual trigger, such as larval movement. In cases where predation by adult yellow perch is found to be significant, it would be fruitful to determine whether larvae develop a behavioral refuge from predation by reducing their movement and feeding activity in the presence of adult yellow perch. This behavior would indicate a compromise between maximizing growth rate and minimizing mortality risk, which has been observed in adult and juvenile fish (Skalski and Gilliam 2002; Werner et al. 1983) but has not been reported for the larval stage. This finding merits further study, particularly in systems in which cannibalism is thought to be important.

Date of hatch distributions of larval survivors changed in the model in response to increases in size variability resulting from variation in mean growth rate. Low growth rates result in higher mortality and seem to favor larvae hatched later in the larval period, while higher growth rates result in lower overall mortality and no net survival benefit relative to $\mathrm{DOH}$. This appears to result from late-hatch larvae being the smallest larvae in the system at the time when mortality is most size-dependent. Nonetheless, the survival pattern of a cohort with a high mean growth rate is still dependent on $\mathrm{DOH}$ as the survival advantage shifts from late-hatch to early-hatch individuals as the larval period progresses. These conclusions would be altered if growth rate and $\mathrm{DOH}$ were not independent in the model and this will be an important avenue of future model analysis. However, the key point is that even when size-dependent vulnerability to predation is due largely to changes in growth rate, mortality is still DOHdependent and analysis of patterns in the $\mathrm{DOH}$ distribution will be informative regarding the effect of size-dependent predation on individual survival.

The relationship between growth rate variability and the intensity of size-dependent predation has been observed in previous individual-based model analyses (Pepin 1989; Rice et al. 1993; Cowan et al. 1996). However, these analyses did not include an examination of the resulting patterns in $\mathrm{DOH}$ distribution, which are informative for the comparison of model results to similar data from natural populations. Sizeindependent mortality, as well as size-dependent mortality acting on low size variability, favored survivors that hatched after peak hatch. In contrast, when size variability was increased by doubling the mean growth rate, the DOH distribution of survivors no longer favored later-hatched larvae.

One surprising result of the individual-based modeling analysis was that patterns in the characteristics of survivors did not change among the different predators tested in this experiment. Cowan and Houde (1992) found differences in 
predators to be an important factor in larval survival, but their study involved comparisons of predators across a wider taxonomic and behavioral range than our work. Similarity in effect of predation among predators in our experiments was likely due to the fact that encounters between large alewife $(>160 \mathrm{~mm}$ TL) and small larvae $(>7 \mathrm{~mm}$ TL) in the model were rare, and it was at the highest predator-prey size ratios (>20) that alewife capture efficiency and attack behavior deviated strongly from that of the other fish predators. At other size ratios, larval size is likely more important to individual vulnerability to predation than variance in size selectivity among these three fish predators.

When larvae were exposed to a predation pulse during the larval period, larval vulnerability to predation was highly dependent on DOH. Larvae that hatched in the 5-7 days preceding the predation period were expected to be more vulnerable to size-dependent predation by alewife than larvae hatched significantly before the predation period. As expected, larvae hatched during or preceding the predation window had lower survival than larvae born at other times, but the impact that this had on cohort survival and the $\mathrm{DOH}$ distribution of survivors depended on what portion of the cohort was affected. The lowest overall survival occurred when the predation window was near or immediately after peak hatch (days $11-15$ or 16-20). The DOH distribution of survivors from this predation scenario also exhibited the highest survival advantage for later-hatched larvae and closely resembled a DOH pattern that was not size-dependent. As the predation window was placed successively later in the larval period, the non-selective signature (increased survival of later-hatched larvae), as well as the mortality rate, decreased. Just as in the growth rate variability experiment, high mortality is associated with a survival advantage for later-hatched larvae, and this advantage is reflected in the DOH distribution of survivors.

Our results suggest that not only is variance in $\mathrm{DOH}$ important to the full description of size variability, but it may provide a valuable detection tool for the selective signature left in characteristics of survivors of the larval stage. These subtle shifts in survival among different subcohorts can have dramatic effects on a subcohort's contribution to the year class, and IBM analysis can be a valuable tool for detecting even these relatively small shifts in the DOH distribution. In a similar model analysis of the timing of predation, Paradis et al. (1999) reported that a predation pulse during the early larval period favored smaller and presumably later-hatching individuals, but if the predator pulse occurred later in the larval period, then this pattern diminished. Their results support ours; however, detection of this pattern in larval size data from the field would be complicated by changes in growth rate among daily subcohorts. Rice et al. (1997) stated that size-selective mortality may be masked and difficult to detect in size data of survivors if reversals in selection occur during the life stage of interest. Date of hatch distributions would suffer from the same limitations, except they can be estimated at multiple points during the larval period and continually compared with the initial DOH distribution. Changes in the DOH distribution over the larval period observed in model simulations are also detectable in field data and may prove valuable for detecting size-selective mortality for a given cohort and making comparisons between cohorts.
In this way, we can use the individual-based model as a tool for measuring the relative effects of sources of growth rate variation and sources of mortality on the $\mathrm{DOH}$ distribution of survivors. In turn, we can provide information on the importance of these factors to year-class strength based on how the $\mathrm{DOH}$ distributions resulting from model analysis match up to comparable field data. The utility of field data for identifying important sources of larval mortality has been questioned based on the differences in scale between traditional field sampling protocols and ecological effect (Pepin 1989, 2004). The combined use of field-collected data on larval DOH distributions and IBM analysis may provide a better tool set for elucidating the complex patterns of larval survival.

In general, size-selective predation on larval yellow perch in Lake Michigan may be weakly correlated with year-class strength at present because of low spatial overlap with predators at vulnerable sizes and densities. Size-selective predation is likely to play a stronger role in smaller systems that are more productive. Predation has been found to be important to year-class strength in other populations of yellow perch (Campell 1998; Mayer et al. 2001). Our conclusions regarding the current importance of predation in Lake Michigan represent an important difference between Lake Michigan and other systems.

An analysis of these differences is warranted before applying lessons learned from examination of perch populations in other systems to our understanding of population dynamics of yellow perch in Lake Michigan. In particular, differences in the importance of sources of mortality such as predation between yellow perch populations in Lake Michigan and yellow perch populations in other systems may be associated with differences in the size of the pelagic habitat; an increase in available habitat will affect local larval retention and the amount of overlap between predators and prey. The application of both field data analysis and individualbased models to the examination of characteristics of larval survivors is a valuable tool for detecting differences in patterns of size-dependent larval mortality. The individual-based model developed as a part of this analysis will be coupled with field data from systems in which predation is thought to be important to larval survival, such as Green Bay, in order to further improve our understanding of recruitment for larval yellow perch.

\section{Acknowledgements}

We thank Amy Spencer, Chris Heyer, Jeff Neuse, Melanie Rhodes, Andy Evans, Steve Yeo, John Bridges, and Brian Degan for their assistance in designing and conducting experiments and processing samples. All of our experiments were conducted at the Great Lakes WATER Institute and we thank the Institute staff for their guidance and support in maintaining larval yellow perch in the laboratory. We thank our fellow members of the Lake Michigan Yellow Perch Task Group for their input and assistance in the completion of this research. This work was funded by the University of Wisconsin Sea Grant Institute under grants from the $\mathrm{Na}$ tional Sea Grant College Program, National Oceanic and Atmospheric Administration, US Department of Commerce 
(Federal Grant No. NA86RG0047, Project No. R/LR-75), and matching funds from the State of Wisconsin.

\section{References}

Bailey, K.M., and Batty, R.S. 1983. A laboratory study of predation by Aurelia aurita on larval herring (Clupea harengus): experimental observations compared with model predictions. Mar. Biol. 72: 295-310.

Bailey, K.M., and Houde, E.D. 1989. Predation on eggs and larvae of marine fishes and the recruitment problem. Adv. Mar. Biol. 25: $1-83$.

Brabrand, A. 1995. Intra-cohort cannibalism among larval stages of perch (Perca fluviatilis). Ecol. Freshw. Fish, 4: 70-76.

Brandt, S.B., Mason, D.M., MacNeill, D.B., Coates, T., and Gannon, J.E. 1987. Predation by alewives on larvae of yellow perch in Lake Ontario. Trans. Am. Fish. Soc. 116(4): 641-645.

Breck, J.E., and Gitter, M.J. 1983. Effect of fish size on the reactive distance of bluegill (Lepomis macrochirus) sunfish. Can. J. Fish. Aquat. Sci. 40: 162-167.

Campell, E.A. 1998. Predation by small walleyes on yellow perch: effects of prey size distribution. Trans. Am. Fish. Soc. 127: 588-597.

Clapp, D., and Makauskas, D. 2002. Status of yellow perch in Lake Michigan and yellow perch task group progress report. Lake Michigan Technical Committee, Duluth, Minnesota.

Cowan, J.H., and Houde, E.D. 1992. Size-dependent predation on marine fish larvae by ctenophores, scyphomedusae and planktivorous fish. Fish. Oceanogr. 1: 113-126.

Cowan, J.H., Houde, E.D., and Rose, K.A. 1996. Size-dependent vulnerability of marine fish larvae to predation: an individualbased numerical experiment. ICES J. Mar. Sci. 53: 23-37.

Crecco, V., and Savoy, T. 1985. Effects of biotic and abiotic factors on growth and relative survival of young American shad (Alosa sapidissima) in the Connecticut River. Can. J. Fish. Aquat. Sci. 42: 1640-1648.

Crowder, L.B. 1980. Alewife, rainbow smelt and native fishes in Lake Michigan: competition or predation? Environ. Biol. Fishes, 5(3): 225-233.

Crowder, L.B., and Binkowski, F.P. 1983. Foraging behaviors and the interaction of alewife, Alosa pseudoharengus, and bloater, Coregonus hoyi. Environ. Biol. Fishes, 8(2): 105-113.

Fabrizio, M.C., Adams, J.V., and Curtis, G.L. 1997. Assessing prey fish populations in Lake Michigan: comparison of simultaneous acoustic-midwater trawling and bottom trawling. Fish. Res. 33: $37-54$.

Francis, J.T., Robillard, S.R., and Marsden, J.E. 1996. Yellow perch management in Lake Michigan: a multi-jurisdictional challenge. Fisheries, 21(2): 18-21.

Fulford, R.S. 2003. Food-web interactions of larval yellow perch, Perca flavescens, in Lake Michigan: implications for recruitment. Ph.D. dissertation, North Carolina State University, Raleigh, N.C.

Gerritsen, J., and J.R. Strickler. 1977. Encounter probabilities and community structure in zooplankton: a mathematical model. J. Fish. Res. Board Can. 34: 73-82.

Gibson, R.N., and Ezzi, I.A. 1992. The relative profitability of particulate-feeding and filter-feeding in the herring, Clupea harengus L. J. Fish Biol. 40(4): 577-590.

Heyer, C.J. 2000. Understanding maternal effects as a recruitment mechanism in Lake Michigan yellow perch (Perca flavescens). Master's thesis, University of Maryland, College Park, Md.

Hollander, M., and Wolfe, D.A. 1999. Nonparametric statistical methods. 2nd ed. John Wiley and Sons, Inc., New York.
Houde, E.D. 1969. Sustained swimming ability of larvae of walleye (Stizostedium vitreum) and yellow perch (Perca flavescens). J. Fish. Res. Board Can. 26: 1647-1659.

Houde, E.D. 1987. Fish early-life dynamics and recruitment variability. Am. Fish. Soc. Spec. Symp. 2: 17-29.

Houde, E.D. 1989. Subtleties and episodes in the early life of fishes. J. Fish Biol. 35(Suppl. A): 29-38.

Janssen, J. 1976. Feeding modes and prey size selection in the alewife (Alosa pseudoharengus). J. Fish. Res. Board Can. 33(9): 1972-1975.

Leggett, W.C., and Deblois, E. 1994. Recruitment in marine fishes: is it regulated by starvation and predation in the egg and larval stages. Neth. J. Sea Res. 2: 119-134.

Letcher, B.H., Rice, J.A., Crowder, L.B., and Rose, K.A. $1996 a$. Variability in survival of larval fish: disentangling components with a generalized individual-based model. Can. J. Fish. Aquat. Sci. 53: 787-801.

Letcher, B.H., Rice, J.A., Crowder, L.B., and Binkowski, F.P. 1996 . Size-dependent effects of continuous and intermittent feeding on starvation time and mass loss in starving yellow perch (Perca flavescens) larvae and juveniles. Trans. Am. Fish. Soc. 125: 14-26.

Luecke, C., Rice, J.A., Crowder, L.B., Yeo, S.E., and Binkowski, F.P. 1990. Recruitment mechanisms of bloater in Lake Michigan: an analysis of the predatory gauntlet. Can. J. Fish. Aquat. Sci. 47(3): 524-532.

Mayer, C.M., Rudstam, L.G., Mills, E.L., Cardiff, S.G., and Bloom, C.A. 2001. Zebra mussels (Dreissena polymorpha), habitat alteration, and yellow perch (Perca flavescens) foraging: system-wide effects and behavioural mechanisms. Can. J. Fish. Aquat. Sci. 58(12): 2459-2467.

Miller, T.J. 1988. Larval size and recruitment mechanisms in fishes: towards a conceptual framework. Can. J. Fish. Aquat. Sci. 45: $1657-1670$.

Miller, T.J. 1997. The use of field studies to investigate selective processes in fish early life history. In Early life history and recruitment in fish populations. Edited by E.A. Trippel. Chapman and Hall, New York. pp 197-224.

Neter, J., Wasserman, W., and Kutner, M.H. 1990. Applied linear statistical models. 3rd ed. Irwin, Boston, Mass.

Pampel, F.C. 2000. Logistic regression: a primer. Sage Publications, Thousand Oaks, Calif.

Paradis, A.R., Pepin, P., and Brown, J.A. 1996. Vulnerability of fish eggs and larvae to predation: review of the influence of the relative size of prey and predator. Can. J. Fish. Aquat. Sci. 53(6): 1226-1235.

Paradis, A.R., Pepin, M., and Pepin, P. 1999. Disentangling the effects of size-dependent encounter and susceptibility to predation with an individual-based model for fish larvae. Can. J. Fish. Aquat. Sci. 56: 1562-1575.

Pepin, P. 1989. Predation and starvation of larval fish: a numerical experiment of size- and growth-dependent survival. Biol. Oceanogr. 6: $23-44$.

Pepin, P. 2004. Early life history studies of prey-predator interactions: quantifying the stochastic individual responses to environmental variability. Can. J. Fish. Aquat. Sci. 61: 659-671.

Pepin, P., Shears, T.H., and deLafontaine, Y. 1992. Significance of body size to the interaction between a larval fish, Mallotus villosus, and a vertebrate predator, Gasterosteus aculeatus. Mar. Ecol. Prog. Ser. 81: 1-12.

Rice, J.A., Crowder, L.B., and Holey, M.E. 1987. Exploration of mechanisms regulating larval survival in Lake Michigan bloater: a recruitment analysis based on characteristics of individual larvae. Trans. Am. Fish. Soc. 116: 703-718. 
Rice, J.A., Crowder, L.B., and Marschall, E.A. 1997. Predation on juvenile fishes: dynamic interactions between size-structured predators and prey. In Early life history and recruitment in fish populations. Edited by E.A. Trippel. Chapman and Hall, New York. pp. 333-356.

Rice, J.A., Miller, T.J., Rose, K.A., Crowder, L.B., Marschall, E.A., Trebitz, A.S., and DeAngelis, D.L. 1993. Growth rate variation and larval survival: inferences from an individual-based size dependent predation model. Can. J. Fish. Aquat. Sci. 50: 133-142.

Ryer, C.H., Lawton, A., Lopez, R.J., and Olla, B.L. 2002. A comparison of the functional ecology of visual vs. nonvisual foraging in two planktivorous marine fishes. Can. J. Fish. Aquat. Sci. 59(8): $1305-1314$.

SAS Institute Inc. 2002. Statistical analysis system. Ver. 8.2. SAS Institute Inc., Cary, N.C.

Scharf, F.S., Juanes, F., and Rountree, R.A. 2000. Predator size prey size relationships of marine fish predators: interspecific variation and effects of ontogeny and body size on trophic-niche breadth. Mar. Ecol. Prog. Ser. 208: 229-248.
Sharp, G.D. 1987. Averaging the way to inadequate information in a varying world. Am. Inst. Fish. Res. Biol. Briefs, 16: 3-4.

Shroyer, S.M., and McComish, T.S. 2000. Relationship between alewife abundance and yellow perch recruitment in southern Lake Michigan. N. Am. J. Fish. Manag. 20: 220-225.

Sissenwine, M.P. 1984. Why do fish populations vary? In Exploitation of marine communities. Edited by R. May. Springer-Verlag, Berlin. pp. 59-94.

Skalski, G.T., and Gilliam, J.F. 2002. Feeding under predation hazard: testing models of adaptive behavior with stream fish. Am. Nat. 160(2): 158-172.

Sogard, S. 1997. Size-selective mortality in the juvenile stage of teleost fishes: a review. Bull. Mar. Sci. 60(3): 1129-1157.

Tarby, M.J. 1974. Characteristics of yellow perch cannibalism in Oneida Lake and the relation to first year survival. Trans. Am. Fish. Soc. 103(3): 462-471.

Werner, E.E., Gilliam, J.F., Hall, D.J., and Mittelbach, G.G.. 1983. An experimental test of the effects of predation risk on habitat use in fish. Ecology, 64(6): 1540-1548. 
Copyright of Canadian Journal of Fisheries \& Aquatic Sciences is the property of NRC Research Press and its content may not be copied or emailed to multiple sites or posted to a listserv without the copyright holder's express written permission. However, users may print, download, or email articles for individual use. 